\title{
Kapitel 7 \\ Der Wortschatz: das Einfache und das Komplexe
}

\section{Einstieg}

Ein Gesetz kann z. B. so heißen: „Gesetz zur zielgenauen Stärkung von Familien und ihren Kindern durch die Neugestaltung des Kinderzuschlags und die Verbesserung der Leistungen für Bildung und Teilhabe“ oder so „Starke-FamilienGesetz“. Der erste Titel - es ist sozusagen der fachliche Klarname des im Jahr 2019 unter der Federführung der Familienministerin eingebrachten Gesetzes - wird als typischer Vertreter eines in seiner Komplexität unverständlichen und monströsen Verwaltungsdeutsch kritisiert. (Man vergleiche dazu auch die Einstiegspassage zu Kapitel 5.) Der zweite Titel stieß wie die ähnlich gestrickten Bezeichnungen „GuteKita-Gesetz“ und „Respektrente“ auch nicht nur auf Gegenliebe, sondern wird als „PR-Sprech“ oder gar als „Kinder(garten)sprache“ bezeichnet. ${ }^{1}$ Zudem werde so mit dem Gesetzentwurf gleich dessen Bewertung mitgeliefert und damit versucht, die politische Debatte zu manipulieren.

Aus linguistischer Perspektive stehen sich mit den eingangs genannten Alternativen zwei unterschiedliche Bezeichnungsstrategien gegenüber, eine syntaktische und eine lexikalische: Die syntaktische arbeitet mit der Attribution, die lexikalische mit der Komposition. In beiden Fällen wird ein Kopfsubstantiv, hier das Substantiv Gesetz, modifiziert, also näher bestimmt. Wenn die lexikalische Strategie angewandt wird, wird damit ein neues Element des deutschen Wortschatzes kreiert. ${ }^{2}$ Das erste Unterkapitel greift diese unterschiedlichen Verfahren auf und befasst sich unter dem Stichwort ,frei versus fest ${ }^{\star}$ mit der Differenz zwischen syntaktischer Fügung und Wortschatzeinheit.

Zwar gilt der Wortschatz gegenüber der Syntax als das vergleichsweise fester gefügte Teilsystem einer Sprache, da er uns anders als jene mit vorgefertigtem Sprachmaterial versorgt. Es gibt aber doch auch zahlreiche Gelegenheitsbildungen, die schnell in Mode und ebenso schnell wieder aus der Mode kommen. Nicht jedes neu geprägte Wort geht in den Allgemeinbesitz der Sprachgemeinschaft über. Was einigermaßen stabil bleibt, ist auf jeden Fall der Vorrat an einfachen Wörtern, den ,Simplizia‘, wie Staub, fein, sehen usw. Neue Simplizia zu erfinden und erfolgreich zu verbreiten, dürfte schwerfallen. Wort(neu)schöpfung ist, zumindest in diesem Bereich, kaum möglich. Erfolgversprechender sind folgende Neologismenstrategien: Man kann bewährten Wörtern neue Bedeutungen unterlegen, etwa wenn heute, vor allem unter jungen Leuten, abhängen im Sinne von ,sich meist zusammen mit anderen passiv entspannen' gebraucht wird. Der wichtigste Trend ist hier aber die Übernahme englischer Begriffe (wie Fan oder skypen). Die Verfahren, 
mit denen wir ohne Eingriff - zumindest keinen auf der Ausdrucksseite - in das in einer Sprache Etablierte zu Neuwörtern kommen, behandeln wir im zweiten Unterkapitel.

Wortschatzerweiterung ist aber im Wesentlichen ein „Aus-alt-mach-neu“. An erster Stelle ist im Deutschen die Komposition zu nennen, wie in den oben genannten Gesetzesnamen oder z. B. in Erdüberlastungstag. Sie macht sich besonders gern auch englische Wörter zunutze, wenn aus oder mit englischen Bestandteilen neue Wörter wie Fanfiction, Fanmeile oder Fitness-Fan konstruiert werden, die dann schließlich ziemlich deutsch klingen. Die Zusammensetzung ist aber nur einer von zwei Pfeilern der Wortbildung: Wird bei ihr aus zwei Inhaltswörtern - relativ beliebiger Wortartzugehörigkeit - ein neues Wort zusammengebaut wie bei Feinstaub, klimaneutral, vorgestern oder fernsehen, können wir bei der Ableitung (oder ,Derivation') aus nur einem Substantiv, Adjektiv, Adverb oder Verb(-Stamm) ein neues Wort - oder auch mehrere Wörter - bilden wie bei bestäuben und entstauben, entfernen, gestrig oder versehen und absehen. „Aus-zwei-mach-eins“ versus „Aus-einem-mach-viele“. Daneben gibt es hier einige weniger wichtige Verfahren, auf die wir nicht im Einzelnen eingehen können. So stellt die Wortmischung eine besonders krasse Form des „Aus-zwei-mach-eins“ dar, wie etwa bei Zoodles als Bezeichnung für aus Zucchini hergestellte nudelförmige Nahrungsmittel. Mit seiner aus dem Englischen übernommenen Schreibweise und Pluralbildung steht dieses Neuwort wieder für die Liebe zum Anglizismus.

Auch die verschiedenen Formen der Kurzwortbildung sind in Zeiten radikaler Beschleunigung sprachübergreifend häufig anzutreffen. Da kann der zweite Teil eines Wortes entfallen wie im Jargon des Schulwesens bei Abi, Bio oder Mathe. Oder der erste Teil entfällt wie bei Cello (zu Violoncello) oder Bus (zu Omnibus). Auch Englisch und Französisch kennen neben den Langformen die Kurzwörter cello und bus, das Ungarische nur die Kurzformen cselló und busz, während etwa das Polnische es bei wiolonczela und autobus belässt. Nur die Wortmitte der Langform bewahren (oder variieren) manche Kurznamen wie Lisa oder Basti; man vergleiche auch englisch Bess oder das aus dem Russischen stammende Sascha (zu Alexander). Manche Kurzwörter sind auch aus verschiedenen Teilen eines Wortes zusammengeschnitten wie etwa LKW (zu Lastkraftwagen) oder Kita (zu Kindertagesstätte). Bei LKW oder auch ADAC sprechen wir das Kurzwort nach Maßgabe der Namen der aneinandergereihten Buchstaben, bei Kita oder Schupo (zu Schutzpolizist) hingegen übernehmen wir zwei Buchstaben vom Anfang der Teilwörter und sprechen sie als leicht gängige „Idealsilben“ aus. ${ }^{3}$

Belassen wir es dabei und konzentrieren uns auf Derivation und Komposition: Das dritte Unterkapitel kontrastiert diese zentralen Verfahren, wie auf der Basis des Bestehenden neue Wörter gebildet werden können, im Einzelnen. 
Benennungsbedarf besteht auch in anderen Kulturen und Sprachen fortwährend. Die möglichen Verfahren zu dessen Deckung unterscheiden sich in den europäischen Sprachen nicht grundsätzlich, wohl aber in der Relevanz und Produktivität der Typen. Während das Deutsche als besonders kompositionsfreudige Sprache gilt, setzen Französisch und Polnisch z. B. in erster Linie auf die Syntax. Feinstaub stehen französisch particules fines (wörtlich ,feine Parti$\mathrm{kel}^{`}$ ) und polnisch drobny pył (wörtlich, feiner Staub') gegenüber und Feinstaubbelastung: émission de particules fines bzw. emisja drobnego pyłu (wörtlich ,Emission von feinen Partikeln / von feinem Staub'). Dem Thema ,Wort- und Begriffsbildung' anderswo widmet sich komprimiert das abschließende Unterkapitel. Auf eklatante Parallelen oder Kontraste bei bestimmten Verfahren gehen wir schon in den vorangehenden Unterkapiteln ein.

\section{Wie frei sind wir in der Syntax? Wie sehr legt uns der Wortschatz fest? Wohin gehören „feste“ Fügungen?}

Schätze finden wir vor, z. B. in Schatzkisten oder Tresoren. In die deutsche Bezeichnung für das Vokabular einer Sprache - sie ist Ende des 18. Jahrhunderts aufgekommen - ist die Vorstellung also eingeschrieben, es gebe einen wertvollen Vorrat an Wortmaterial, aus dem wir nur zu schöpfen haben. Wir haben dies bereits in Kapitel 2 angesprochen. Demgegenüber assoziieren wir mit Grammatik zwar ein rigides Regelwerk oder, weniger normativ, eine Anleitung zu Sprachspielen, aber keineswegs einen Vorrat an „fertigen“ Sätzen oder syntaktischen Fügungen.

Der Gegensatz zwischen frei und fest scheint das Verhältnis von Syntax und Wortschatz gleich in doppelter Hinsicht zu betreffen: Da sind zum einen die unterschiedlichen Funktionen. Der Wortschatz versieht uns in erster Linie mit Zeichen, die wir als mit anderen Sprechern geteilte und immer wieder gebrauchte Instrumente des Kategorisierens und Erschließens der Welt nutzen. Die Syntax erlaubt uns, aus diesem Instrumentarium variable und prinzipiell offene Formen des sprachlichen Handelns zusammenzustellen. Der Unterschied korrespondiert also mit der Unterschiedlichkeit der Funktionen. Das haben wir in Kapitel 2 erörtert.

Zum anderen gibt es einen bedeutenden kognitiven Unterschied. Um als kompetente Sprecherin des Deutschen gelten zu können, muss ich einen hinreichend großen Anteil des „Allgemeinwortschatzes“ dieser Sprache abrufbar in meinem Gedächtnis, und zwar dem so genannten ,Langzeitgedächtnis‘, gespeichert haben. Der Umfang des Abgespeicherten variiert erheblich mit Alter, Bildungstand, Berufsweg und einigen weiteren Variablen: Genannt werden 150.000 bis 200.000 Einheiten, die wir - erwachsene, gebildete Mitteleuropäerinnen und -europäer - als 
Maximum in unserem ,mentalen Lexikon“ gespeichert haben. Das kommt mir erstaunlich viel vor, wenn auch die „extramentalen“ Wörterbücher, etwa das „Oxford English Dictionary“ noch erheblich mehr Einträge umfassen mögen (vgl. Kapitel 2, Abschnitt 2.1). Die Psycho- und die Neurolinguistik haben herausgefunden, dass das mentale Lexikon nicht alphabetisch, sondern nach Art eines Netzwerks organisiert ist. Natürlich speichern wir einerseits den Klang, die Lautstruktur, aber auch die syntaktische Kategorie und die Bedeutung eines Wortes ab. Und offenbar geschieht dies in verschiedenen Arealen unseres Gehirns.

Wir verknüpfen Wörter aber auch nach verschiedenen Prinzipien mit zahllosen anderen Wortschatzeinheiten. Assoziativ verknüpft sind Wörter z. B. über lautliche Ähnlichkeit oder über die Zugehörigkeit zur selben Wortfamilie: Von sehen führt ein „Link“ zu Sicht und von dort zu Ansicht, sichtbar und sichten. Bedeutsam sind vor allem auch die semantischen Netze, die sich nach semantischen Relationen wie Über- und Unterordnung oder Bedeutungsverwandtschaft knüpfen lassen: sehen ist ein Unterbegriff zu wahrnehmen und bedeutungsverwandt mit betrachten, erblicken, schauen usw. Schließlich führen Wege auch zu den häufigsten und wichtigsten ,Kookkurrenten“ eines Wortes. Das Wort Sicht z. B. kommt bevorzugt zusammen mit heutig vor, und zwar in der Kombination bzw. ,Kollokation“ aus heutiger Sicht. Diese Kollokation steht anscheinend gattungs- bzw. teilkorpusübergreifend in einer nach der Frequenz des Zusammenvorkommens geordneten Statistik vorn: Sie hält den Spitzenplatz in verschiedenen Teilkorpora von DeReKo, nämlich sowohl in „Belletristik des 20. und 21. Jahrhunderts“ als auch im „Wikipedia-Korpus 2011“ als auch in einem Zeitungskorpus, nämlich dem „Mannheimer Morgen“ der Jahrgänge 1995 bis 2018. Allerdings folgen im Belletristik-Korpus dann Partner wie frei (in hatte freie Sicht auf) oder versperrte (in versperrte die Sicht auf), während in Wikipedia Sicht sich vor allem mit Adjektiven wie historisch, geologisch, ökologisch zu Kollokationen wie in/aus historischer Sicht verbindet. Im Zeitungskorpus folgen auf den nächsten Plätzen: seine Sicht der Dinge und auf lange Sicht. ${ }^{4}$ Das spiegelt ganz schön wider, dass wir uns kommunikativ hin und her bewegen zwischen dem allgemein Geteilten und dem Besonderen und Individuellen. Narrative Texte bauen Sicht bevorzugt in die Präsentation von Szenarios ein, für Zeitungstexte ist Sicht in erster Linie das Tor zur Meinungsvielfalt, während bei eher instruktiven Texten (Wikipedia) die Sicht der einzelnen Disziplinen oder auch die des Verfassers - vgl. aus meiner / unserer Sicht - die Hauptrolle spielt. Beim Zuhören entwickeln wir übrigens ein intuitives Gespür für die Enge der Beziehung zwischen möglichen Kookkurrenzpartnern: Wenn ich „und er wiederholte das“ höre, warte ich nur darauf, dass mein Gegenüber mit „gebetsmühlenartig“ fortfährt.

Im mentalen Lexikon bildet ein Wort also einen Knoten in einer Art Spinnennetz, von dem aus sich in alle Dimensionen Verbindungslinien ausbreiten zu anderen Knoten, die ihrerseits untereinander verknüpft sein können. Darauf jedenfalls 


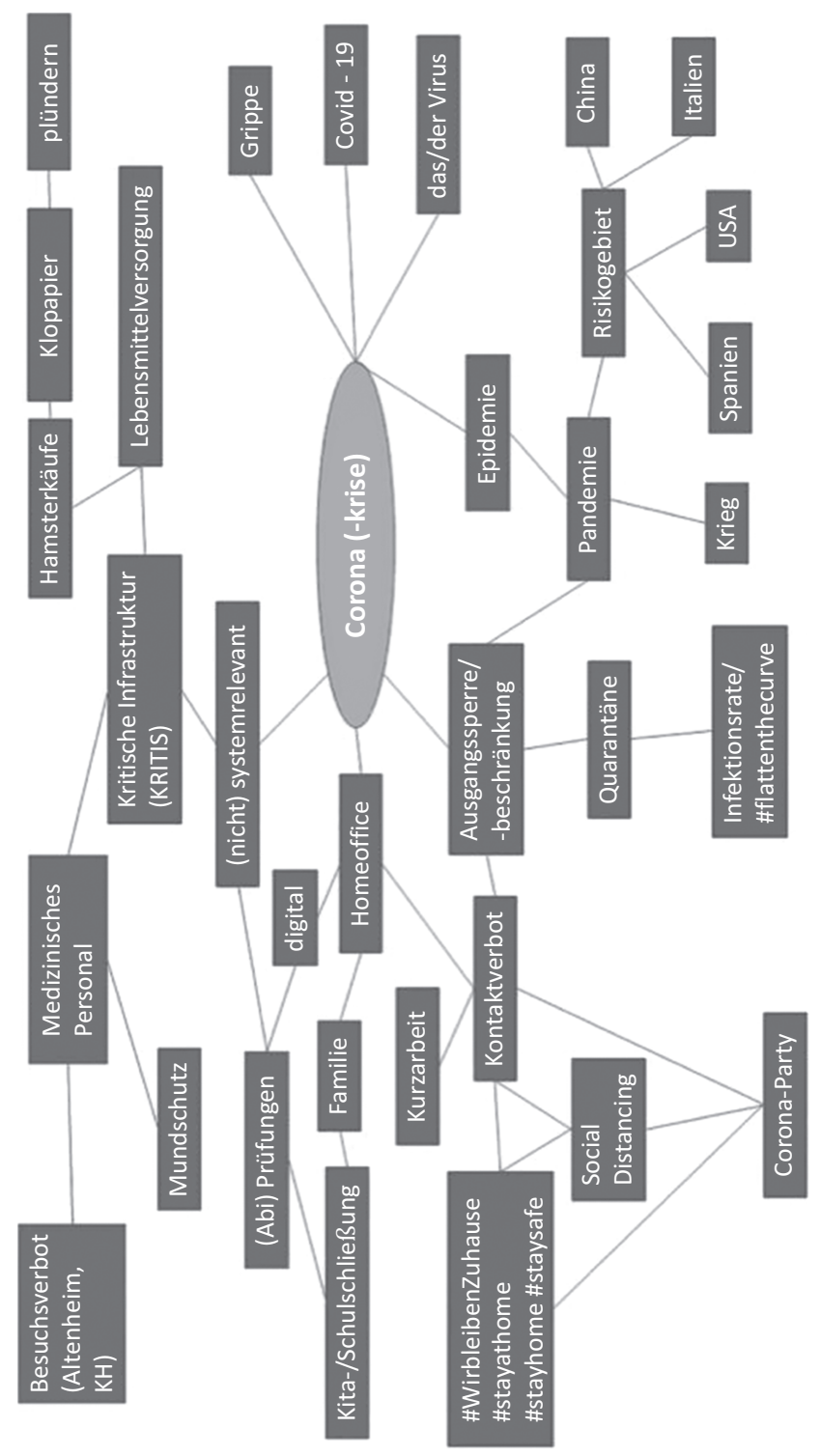

Abb. 17: Wortnetz um Corona. 
läuft die übliche Form der Visualisierung hinaus. Ich illustriere das an dem „Wortnetz“, das sich Anfang April 2020 um Corona „entspinnt“, vgl. dazu Abb. 17. ${ }^{5}$

Sätze und andere syntaktische Konstrukte hingegen speichern wir nur in Ausnahmefällen im Langzeitgedächtnis ab. Das mag auf der individuellen Ebene dann geschehen, wenn ein Ausspruch eines Menschen eine bleibende Spur hinterlassen hat. Meine Großmutter z. B. ist mir durch ein häufig bei ihren Erzählungen von früher eingestreutes „einst und jetzt“ erinnerlich. Dem kollektiven Gedächtnis hingegen werden neben Zitaten von großer politischer oder historischer Tragweite wie z. B. Walter Ulbrichts Aussage „Niemand hat die Absicht, eine Mauer zu errichten“ vom 15. Juni 1961 - vor allem so genannte ,feste Fügungen“ einverleibt. In festen Fügungen sind die ansonsten ganz oder überwiegend variablen Positionen eines syntaktischen Musters mit bestimmtem Wortmaterial gefüllt, und die so eingefrorene Verkettung wird als Ganze dem mentalen Lexikon anvertraut. Die festen Fügungen schwarze Kasse, gelber Sack (bzw. Gelber Sack), ${ }^{6}$ blinder Passagier instanziieren das syntaktische Muster ,attributives Adjektiv + Kopfsubstantiv'. Die Fügungen auf Anhieb, in Windeseile oder bis zum Hals haben die Struktur von Präpositionalphrasen mit „freien“ Gegenstücken wie auf Zuruf oder bis zum Ohrläppchen.

Ein spezielles Muster verkörpern Paar- oder Zwillingsformeln wie deutsch $a b$ und zu, hin und her, ganz und gar, fix und fertig; Haus und Hof, Sack und Pack, Kind und Kegel; schalten und walten, kommen und gehen. Wie diese Beispiele zeigen, gibt es diese Koordinationen in verschiedenen Wortarten. Ihre beiden Teile bedeuten oft fast das Gleiche oder sie decken wie bei hin und her, Freund und Feind, kommen und gehen oder eben auch Großmutters einst und jetzt gemeinsam die Pole eines semantischen Feldes ab. Ihre Zusammenstellung ist also kaum einer inhaltlichen Notwendigkeit, aber auch nicht dem Zufall geschuldet, sondern folgt einem ganzen Bündel von Gestaltungsprinzipien: Da ist zum einen gerade bei den nominalen Zwillingsformeln - die Orientierung an einer (bis in die Verästelungen unseres Alltagslebens) erweiterten Nominalhierarchie: ${ }^{7}$ Das jeweils höher Rangierende, das Salientere, geht voraus, z. B.: Belebtes vor Unbelebtem wie in Mensch und Maschine oder Pferd und Wagen, männlich vor weiblich wie in Mann und Frau oder Wichtigeres vor weniger Wichtigem bei Hopfen und Malz. Zum anderen schmeicheln Paarformeln unserem Ohr durch Endreime, Alliterationen und andere klangliche Übereinstimmungen (Rat und Tat, Kind und Kegel, angst und bange). Neben der semantischen Salienz ist auch das Gesetz der ,aufsteigenden Silbenzahl' verantwortlich für die in aller Regel nicht umkehrbare Reihenfolge der beiden Teile. Und schließlich soll auch die Akzentverteilung den für das Deutsche gültigen Regularitäten der Abfolge von betonten und unbetonten Silben im Wort und in der größeren metrischen Einheit, dem ,Fuß', nicht zuwiderlaufen. Allerdings ist die Salienzordnung allen anderen Beschränkungen vorgeordnet. So verstoßen Hopfen und Malz, (bei) Wasser und Brot zwar gegen 
das Prinzip der ansteigenden Silbenzahl und sind auch metrisch weniger gut als Malz und Hopfen / Brot und Wasser, aber das im wahren Leben, speziell für das Bierbrauen oder das Überleben, Essenziellere siegt.

Zwillingsformeln sind sprachübergreifend weit verbreitet. Das mag teilweise auch auf ihren Ursprung in der wirkungsmächtigen Rechtssprache zurückzuführen sein, wie z. B. bei englisch to have and hold oder deutsch Haus und Hof, Treu und Glauben. Dabei ist zu erwarten, dass die Gestaltungsprinzipien, bis auf die einzelsprachlichen Akzentregeln verhaftete metrische Wohlgeformtheitsbedingung, z. B. auch im Englischen, Französischen, Russischen, Polnischen oder Ungarischen Geltung haben. ${ }^{8}$ Englische Beispiele sind: on and off (vgl. ab und zu, hin und wieder), neat and tidy (vgl. geschniegelt und gebügelt), done and dusted (vgl. unter Dach und Fach); dust and ashes (vgl. Blut und Asche), law and order (vgl. Recht und Ordnung), rise and shine (vgl. raus aus den Federn). Französisch steuert z. B. bei: sain et sauf (vgl. gesund und munter); corps et biens (vgl. Mann und Maus); aller et venir (vgl. kommen und gehen). Beispiele aus dem Russischen sind: vdol' i poperek (,kreuz und quer'); den' i noc' (,Tag und Nacht'), fotki i pribautki (,Scherze und Redensarten'), styd $i$ sram (,Schimpf und Schande'). Für Polnisch seien dzień $i$ noc (,Tag und Nacht'), wzdhuz $i$ wszerz (,kreuz und quer'), krótko $i$ węzłowato (,kurz und bündig') genannt, für Ungarisch szégyen és gyalázat (,Schimpf und Schande‘).

Zwillingsformeln können auch anstelle von ,und' durch ,oder' verknüpft sein wie in mehr oder weniger (vgl. englisch more or less) oder in früher oder später und dem gleichbedeutenden französischen tôt ou tard. Redundanz kann sogar mit nachdrücklichem Effekt - durch Wiederholung auf die Spitze getrieben werden wie in deutsch durch und durch, englisch on and on. Eine weitere Variation Präposition statt Konjunktor - führt zu Schulter an Schulter, Zug um Zug. Zudem sind auch Dreifachkombinationen möglich wie Wein, Weib und Gesang oder Blut, Schweiß und Tränen. Nicht selten sind Paarformeln Teil einer umfassenderen Fügung oder Kollokation wie bei mit Mann und Maus untergehen, mit Rat und Tat zur Seite stehen, sich um Kopf und Kragen reden, einem angst und bange werden. Das „Land, wo Milch und Honig fließen“ begegnet schon in der Hebräischen Bibel mehrfach (z. B. Exodus 3.16), und so dürfte die Paarformel in zahlreichen Sprachen für jenes gelobte Land von Frieden und Überfluss stehen. Allerdings nicht zwingend in dieser Reihenfolge. Im Slowenischen etwa soll die Umkehrung med in mleko die übliche Form sein. ${ }^{9}$ Ist da, wie bei den genannten Dreifachformeln, das Prinzip der aufsteigenden Silbenzahl wirksam?

Von besonderer Bedeutung sind um ein Verb herum gebaute Fügungen wie etwas über Bord werfen, den Nagel auf den Kopf treffen, jemandem einen Bären aufbinden oder einen Streit vom Zaun brechen, die jeweils einen für das Verb auch sonst gültigen Valenzrahmen nutzen, wie etwa den Rahmen ,direktes Objekt + Direktivkomplement + Verb ' bei den Fügungen mit werfen und treffen. 
Allen genannten Fügungen ist gemeinsam, dass sie insgesamt, oder, was gewisse Bestandteile angeht, nicht wörtlich zu nehmen sind oder zumindest eine Spezialisierung erfahren haben. Man spricht hier auch von ,Idiomatisierung، Wenn man etwas über Bord wirft, muss man sich nicht auf einem Schiff oder in einem Flugzeug befinden. Es geht einfach darum, sich rigoros einer Einschränkung, der eigenen Bedenken oder einer moralischen Pflicht zu entledigen. Wenn man einen Streit vom Zaun bricht, geht es zwar um einen Streit, das Vom-ZaunBrechen ist aber ein Bild für das unmotivierte „Anzetteln“ desselben. Man muss dafür keine Latte aus dem Zaun zum Nachbarn brechen - eine archaische Streitszene, die wohl als Bildspender diente. Ein blinder Passagier ist nicht im üblichen aktivischen Wortsinn blind, also unfähig zu sehen; aber immerhin hat blind auch in anderen Verbindungen die passivische Bedeutung ,unsichtbar, undurchsichtig, nur scheinbar' wie in blinde Scheibe oder blinde Naht, im Gegensatz zum üblichen ,ohne Sehvermögen‘. Der gelbe Sack ist nicht einfach irgendein flexibles Behältnis in gelber Farbe, sondern in Wikipedia heißt es: „Als Gelben Sack bezeichnet man in Deutschland und Österreich einen dünnen, gelblich transparenten Kunststoffsack, in dem im Rahmen der lokalen Abfallentsorgung leichter Verpackungsmüll abgegeben werden kann.“ Der gelbe Sack steht oft auch metonymisch für das ganze Konzept oder Verfahren dieser Art von Entsorgung.

Die mehr oder weniger ausgeprägte Bedeutungsverschiebung und -spezialisierung ist - oft zusammen mit metaphorischem Sprachgebrauch - der Witz am Gebrauch fester Fügungen: Sie haben sich uns eingeprägt, weil sie auffällig und oft auch bildkräftig und anschaulich sind. Und wir verwenden sie, weil wir selbst mit unserem Sprachgebrauch einprägsam sein wollen. Die Bezeichnung ,Redensart", die in erster Linie für die bildhaften verbalen Fügungen steht, „trifft“ daher, so scheint mir, „den Nagel auf den Kopf“, besser als blutleere sprachwissenschaftliche Termini.

Allerdings gibt es zahlreiche Abstufungen, sowohl was die Festigkeit als auch was die Wörtlichkeit von solchen Fügungen angeht. Die Sprachwissenschaft spricht daher auch gern von Phraseologismen oder Phrasemen, um das nicht immer voll zutreffende Attribut ,fest' zu umgehen. So sind die oben genannten nominalen Fügungen in der Tat fest; man wird kaum variieren oder etwas einfügen. Ist von einem ganz blinden Passagier oder einem schmutziggelben Sack die Rede, haben wir es nicht mehr mit dem, was mit dem Phrasem gemeint ist, zu tun, sondern eher mit sehunfähigen Menschen bzw. mit gewöhnlichen Säcken für beliebige Zwecke. ${ }^{10}$ Das ist auch der Tatsache geschuldet, dass solche nominalen Phraseme eine begriffliche Einheit bezeichnen und damit Substantiven ähneln. Wir kommen darauf im letzten Unterkapitel zurück. Verbale Phraseme sind da gelegentlich flexibler: So findet man in DeReKo neben einen Bären aufbinden auch nicht jeden Bären oder einen rosaroten / silbernen 
Bären aufbinden, und es wird gefragt: „Könnte es sein, Herr Minister, dass Sie der Öffentlichkeit und dem Parlament einen ganz großen Bären aufbinden [...]?“ (Protokoll der Sitzung des Parlaments Landtag Schleswig-Holstein am 27.09.2000).

Es gibt also ein Kontinuum von ganz festen Fügungen über Zwischenstufen bis hin zu Wortverbindungen, die sich gegenüber dem „normalen“ Zusammenvorkommen in syntaktischer Verbindung nur durch mehr oder minder stark erhöhte Frequenz auszeichnen, ohne dass Metaphorik oder Idiomatisierung im Spiel wären. So betrachtet ist aus heutiger Sicht stärker kollokativ (ca. 24.000 Vorkommen im „Archiv geschriebener Sprache“) als aus damaliger Sicht (848 Vorkommen), während aus gestriger Sicht (1 Vorkommen) kollokativ zu vernachlässigen ist.

Manchmal werden feste Fügungen auch als Mehrwort-Lexeme bezeichnet. Das kann in die Irre führen. Ja, gelber Sack oder falscher Fuffziger teilen mit Mehrwegflasche oder Betrüger die Eigenschaft, dass sie als Ganzes im mentalen Lexikon abgespeichert werden, und sie können daher auch in semantischen Netzen mit den jeweils bedeutungsverwandten Lexemen verbandelt werden. Aber die Fügungen sind keine Wörter. Für die Struktur von Wörtern gelten andere Regularitäten als für die syntaktische Struktur. Ich fasse die wichtigsten Unterschiede zusammen:

- Wörter werden nur einmal flektiert, im Deutschen am Wortende; Binnenflexion ist ausgeschlossen.

- Wörter enthalten keine Funktionswörter, also keine Artikel bzw. andere Determinative oder Präpositionen.

- Die Teile von komplexen Wörtern bleiben beisammen; ein Wort wird nur insgesamt im Satz bewegt.

Alle unsere Beispiele für Phraseme verstoßen gegen mindestens eine dieser Regularitäten: Nominale Fügungen (wie gelbe Karte) flektieren doppelt, am Adjektiv und am substantivischen Kopf. Sie verhalten sich also nicht wie Wörter. Noch krasser unwortmäßig verhalten sich verbale Phraseme (wie auf den Busch klopfen, ins Gras beißen), die nicht nur mehrfach flektiert sind, sondern auch Funktionswörter, nämlich Präpositionen, Artikel oder eine Verschmelzung aus beidem (bei ins) enthalten. Zudem folgt das in ihnen enthaltene Verb als Prädikat den syntaktischen Regeln für die Verbpositionierung, ist also in vielen Fällen vom Rest des Phrasems getrennt. Man vergleiche „Nun beiß ich endlich ins Gras, für die restliche Show viel Spaß“ (Nordkurier vom 08.12.2008). Zu den Regularitäten vergleiche man Kapitel 5, Abschnitt 3.2.

Allerdings gilt: Keine Regel ohne Ausnahmen. Es gibt durchaus Wörter, die gegen die erstgenannte Regel verstoßen: Gästebuch, Männerbund und andere haben als ersten Teil des Kompositums eine flektierte Form und zwar eine Plural- 
form. Es handelt sich ja auch um ein Buch für Gäste, nicht für einen einzelnen Gast, und ein Männerbund hat notwendigerweise eine ganze Reihe von Mitgliedern. Das heißt, Pluralmarkierung kann semantisch motiviert sein und ist ein lässlicher Verstoß gegen das Verbot der Binnenflexion. Aber der Normalfall ist der unflektierte Stamm, im Deutschen also der Singularstamm wie in Buchhandlung oder Tierschutzgesetz, obwohl es um den Verkauf von Büchern und den Schutz von Tieren geht. ${ }^{11}$

Bedeutend gravierender ist das Vorkommen eines Kasusmarkers. Wir sagen nicht: Man hüte sich vor *Männermbünden - obwohl die Präposition vor den Dativ fordert und Männern die Dativ-Plural-Form ist. Adjektive können zwar, da ebenfalls semantisch motiviert, gelegentlich in der Komparativ- oder Superlativform den ersten Teil von Komposita bilden (Besserwisser, Höchstform). Die adjektivischen Kongruenzaffixe -e, -er, -en, -em, -es haben aber eine rein syntaktische Funktion und sollten daher im Wort nicht auftreten. Aber auch dazu gibt es einige wenige Ausnahmen, die immer wieder genannt werden, z. B. Wörter wie (die) Langeweile, (das) Hohelied, (der) Hohepriester. Hier findet sich statt des Adjektivstamms, der gewöhnlich in Komposita vorliegt (z. B. Langwelle nicht * Langewelle), eine flektierte Form des Adjektivs. Optional verändern wir auch diese wortinterne Endung noch, die man als unmarkiertes Allerweltsflexiv werten kann, wie z. B. in: Wer leidet hier an Langerweile. $^{12}$

Gegen die zuletzt genannte Beschränkung, das Zusammenbleiben von Wörtern, wird etwa bei aufbegehren und vorlesen und den Partikelverben insgesamt regelmäßig und in großem Stil verstoßen. Diese Ausdrücke kann man aber nicht (oder nicht mehr) als verfestigte syntaktische Verbindungen betrachten. In der „freien“ Syntax verbinden sich Präpositionen wie aus und vor nicht mit Verben. Also bleibt nur, ihnen wohl oder übel einen Sonderstatus als Wörter mit außergewöhnlichen Eigenschaften einzuräumen; vgl. Abschnitt 4.5. Dennoch lehrt uns dieses Beispiel Folgendes: Es ist zwar auf der einen Seite richtig, die Merkmale für eine Unterscheidung zwischen Syntagma und Wort, oder auch allgemeiner zwischen den Kategorien einer Sprache, klar zu bestimmen. Andererseits kann es immer wieder Phänomene geben, auf die diese unterscheidenden Merkmale nur zum Teil zutreffen. Es handelt sich dann um weniger prototypische Exemplare. Bei ihnen kann sich je nach Gewicht der „Verstöße“ die Waagschale in die eine oder andere Richtung neigen, oder aber man ordnet sie als Phänomene einer dritten Art ein. Bei den Phrasemen - das sagt eigentlich schon der Terminus - überwiegen aus meiner Sicht die pro-syntagmatischen Merkmale.

Für das Ende dieses Unterkapitels aufgespart habe ich mir die Glanzlichter unter den festen Fügungen, die Sprichwörter. Ganze Sätze oder auch elliptische Einheiten transportieren hier mehr oder weniger erfahrungsgesättigte Lebensweisheiten und aus ihnen folgende praktische Maximen wie diese: „Es ist noch 
nicht aller Tage Abend“, „In der Not frisst der Teufel Fliegen“, „Aller guten Dinge sind drei“. Oder „Wie gewonnen, so zerronnen“, „Ein Mann, ein Wort“, „Viel Lärm um Nichts“. In aller Regel handelt es sich um Aussagesätze oder entsprechende Kurzformen, die auf der illokutiven Ebene aber in der Regel als Ratschläge, Drohungen oder Warnungen, also als indirekte (oder gar verkappte) direktive Sprechhandlungen zu werten sind. (Sogar das scheinbar nur feststellende „Aller guten Dinge sind drei“ kann ja als Aufmunterung gewertet werden, auch nach zwei vergeblichen Versuchen nicht aufzugeben.) Oder wie Peter Wapnewski formuliert: „Im Sprichwort schlägt sich Erfahrung als Moral nieder; in der Redensart als Stilformel."13 Da Sprichwörter somit ganz aus der Erfahrung schöpfen und direkt auf das praktische Leben abzielen wollen, sind sie noch stärker als andere Fügungen in ihrer Wortwahl und Bildlichkeit nur auf einem bestimmten kulturellen Hintergrund zu verstehen. Für europäische Gesellschaften ist hier die griechisch-römische Antike prägend, z. B. in Form der Fabeln des Äsop („Eine Schwalbe macht noch keinen Sommer“), die Bibel, aber auch die gelehrte und literarische Tradition vom Mittelalter bis hin zu Shakespeare (vgl. den Komödientitel „Much ado about nothing“), Schiller („Die Axt im Haus erspart den Zimmermann“) und Goethe („Grau, teurer Freund, ist alle Theorie“). Da übernimmt ein Autor vom anderen, eine Leser- oder Hörerin macht sich das, was ihr gefällt, zu eigen. Man nennt das auch die ,intertextuelle‘ Qualität von Sprichwörtern wie auch Redensarten allgemein. Überkommene Sprichwörter zeugen jedoch oft auch noch von bäuerlicher Lebensweise und anderen Tätigkeiten im „Schweiße des Angesichts“ und einer feudalen oder ständisch-hierarchischen Sozialordnung: „Was der Bauer nicht kennt, frisst er nicht“, „Die dümmsten Bauern haben die dicksten Kartoffeln“, „Handwerk hat goldenen Boden“, „Schuster bleib bei deinem Leisten“, „Wo gehobelt wird, fallen Späne“, „Wie der Herr, so“s Gescherr“.

Da ein großer Teil des Sprichwortschatzes auf einer im ,alten Europa“ geteilten Lebensweise oder einer überdachenden kulturellen Tradition beruht, nimmt es nicht Wunder, dass es für viele Sprichwörter mehr oder weniger direkte Parallelen in anderen Sprachen gibt. Für das Sprichwort „Bellende Hunde beißen nicht“ soll es direkte Parallelen in 51 europäischen Sprachen geben. ${ }^{14}$ Oftmals ist das Panorama aber etwas unübersichtlicher. Das alte englische Sprichwort „The early bird catches the worm“ fand erst seit Ende der 1980er Jahre, dann aber schnell Eingang ins Deutsche, in der wörtlichen Übertragung „Der frühe Vogel fängt den Wurm“. Bekanntlich gibt es dazu aber bodenständige Konkurrenz mit „Morgenstund hat Gold im Mund“ oder auch dem bedeutungsähnlichen „Wer zuerst kommt, mahlt zuerst“.${ }^{15}$ Voll politischem Hintersinn ist schließlich die Michail Gorbatschow zugeschriebene Variante „Wer zu spät kommt, den bestraft das Leben“. Sie machte steile Karriere im Westen. ${ }^{16}$ 


\section{Wie reichern wir unseren Wortschatz an? Neuschöpfungen, Umdeutungen und Entlehnungen}

Nun wäre aber auch der Eindruck falsch, der Wortschatz enthalte nur auf unabsehbare Dauer Angelegtes, er sei in seinem Bestand absolut stabil. Das kann natürlich gar nicht sein, denn der Wortschatz muss sich ja an den veränderten Bezeichnungsbedarf anpassen, der mit der Veränderung der Welt einhergeht. Es werden folgende Möglichkeiten genannt: Urschöpfung, Bedeutungsveränderung, Entlehnung auf der einen Seite und Wortbildung auf der anderen Seite. Die Wortbildung, „aus Alt mach Neu“, spielt dabei bei weitem die bedeutendste Rolle. Auf sie kommen wir im nächsten Unterkapitel ausführlich zu sprechen.

Den anderen Verfahren ist gemeinsam, dass sie, anders als die Wortbildung, den Wort- und Morphembestand einer Sprache nicht neu mischen und konfigurieren. Diese Verfahren sind daher auch weniger an die Strukturen einer Sprache gebunden als vielmehr an historische und kulturelle Umstände oder auch an Sprachkontakt und Sprachpolitik.

Urschöpfung (oder auch Wortneuschöpfung) dürfte am Anfang jeder Sprachgeschichte gestanden haben, ist aber in Sprachen mit einer langen Entwicklungsgeschichte, schriftlicher Überlieferung und einem in Wörterbüchern kodifizierten lexikalischen Bestand, wie in den europäischen Sprachen, äußerst selten. Unter den Neologismen, die für die 90er, die Nuller- und die Zehnerjahre, also insgesamt für die letzten ca. 30 Jahre auf der Homepage des IDS verzeichnet werden, findet sich nach meinem Urteil keine einzige echte Urschöpfung. ${ }^{17}$

Bedeutungsveränderung, so genannte ,Neubedeutungen' gibt es hingegen einige: Stolperstein hat heute auch die Bedeutung ,Pflasterstein mit einer eingelassenen Messingplatte zur Erinnerung an in der Nazizeit ermordete Bürger eines Ortes'. divers erhielt die Neubedeutung, weder ein weibliches noch ein männliches, sondern ein drittes Geschlecht habend ${ }^{18}{ }^{18}$ Mit einem Netz fängt man heute nicht nur Fische oder nutzt es, wie in früheren Zeiten, beim Wareneinkauf, sondern wir fangen damit elektronisch Informationen ein. Metaphorisch motiviert ist auch Ampel in der schon aus den 1980er Jahren stammenden Neubedeutung ,Parteien-Koalition aus SPD (rot), FDP (gelb) und GRÜNEN (grün)‘. Die Verben texten und wischen werden auf unsere neuen Kommunikationsformen zugeschnitten und haben nun auch die Bedeutungen ,elektronische Kurznachrichten schreiben und senden' bzw. ,mit den Fingern Internet- und Dateiseiten bewegen'. Früher konnte man nur sich selbst einlesen, z. B. in einen schwierigen Text. Heute macht man durch Einlesen einen Text hörbuchtauglich. Partikelverben eignen sich offenbar besonders gut zur Umdeutung, man muss sich nur von der Bewegung, die in der Partikel bzw. Präposition steckt, und der Bedeutung des Simplexverbs neu inspirieren lassen. Man vergleiche das schon erwähnte abhängen oder - auch aus 
dem Bereich Entspannung und Stressabbau - runterkommen oder abschalten. Letzteres ist freilich auch besonders frequent, wenn es um das Kappen der Stromzufuhr geht; dann werden z. B. lebenserhaltende Maschinen oder Atomreaktoren abgeschaltet.

Im Vordergrund stehen allerdings - auch im öffentlichen Bewusstsein und im Diskurs über Sprachthemen - die Entlehnungen in Form von Anglizismen. Es ist eine unbestreitbare Tatsache, dass die Übernahme von lexikalischem Material aus dem Englischen (in der Regel aus dem amerikanischen Englisch) stetig angestiegen ist, Anfang des 20. Jahrhunderts eher zögerlich beginnend - da löst es allmählich das Französische als dominante Gebersprache ab - und dann bis heute nahezu linear ansteigend. ${ }^{19}$ Das Deutsche, so wird behauptet, weise dabei unter den europäischen Sprachen die größte Aufnahmebereitschaft auf. Dies jedoch ist nur ein bisher nicht bewiesener Eindruck und eher ein Ausdruck der Sorge. ${ }^{20}$ Auch die Gründe für die starke Präsenz von Anglizismen sind bekannt und wurden unter positiver wie auch kritischer Wertung vielfach diskutiert. Es sind unter anderem die westliche Orientierung der „alten“ BRD nach dem Zweiten Weltkrieg, verbunden mit Skepsis gegenüber der Beschränktheit des Nationalen und seiner Symbole, zu denen ja auch die Sprache gehören kann, der Einfluss und die Vorreiterrolle der USA auf politischem, wirtschaftlichem, wissenschaftlichem und kulturellem Gebiet sowie das hohe Prestige des nordamerikanischen Lebensstils. Besonders stark ist der Einfluss auf den Gebieten Sport, Mode, Freizeit, (Pop-) Musik und allen voran Computer und Neue Medien. Gerade der letztgenannte Bereich hat durch die umfassende Digitalisierung und die damit verbundenen technischen Neuerungen, durch die grenzüberschreitenden über das Internet laufenden Aktivitäten zu einer rasanten Beschleunigung des Zuwachses an neuem Vokabular geführt. Und der wird eben primär durch Angloneologismen - in einem weiteren Sinne - gedeckt.

Wie groß die Anzahl der Anglizismen im heutigen Deutsch tatsächlich ist dazu gibt es verwirrend viele unterschiedliche Zahlen. Und das nicht von ungefähr. Die Zahlen hängen entscheidend davon ab, was man wo zählt, z. B. nur „reine“ Anglizismen wie Fan oder auch ,Hybride“ wie Fanszene, Fankultur, in einem Wörterbuch der Jugendsprache, einem allgemeinsprachlichen Wörterbuch oder in einem standardsprachlichen Korpus. Ich nenne hier nur die in Eisenberg (2013c) vorgelegten Zahlen, die sich auf alle Substantive, Verben, Adjektive und Adverbien - und zwar einschließlich von hybriden Formen - aus einem Textkorpus beziehen, das im Hinblick auf die Textsortenmischung als repräsentativ für die geschriebene Standardsprache zu betrachten ist. Für das den Zeitraum von 1995 bis 2004, also fast die „Jetztzeit“ umfassende Teilkorpus wurde ein Anglizismen-Anteil von 3,5 \% am Gesamtbestand der Lexeme dieser Wortarten ermittelt. Jede 200. Form im laufenden Text ist ein Anglizismus, und das bedeutet, dass 
man etwas mehr als zwei Vorkommen von Formen dieser Lexeme auf jeder Seite vorfindet. Gegenüber dem Bestand des etwa gleich großen Teilkorpus aus der Zeit von 1905 bis 1914 ergibt sich eine Steigerung um das Zehnfache: Dort betrug der Bestand 0,35 \%, und etwa jede 2.500. Form war ein Anglizismus. Man stieß also nur auf jeder fünften Seite auf einen.

Wie man diesen Zuwachs bewertet, hängt von verschiedenen Faktoren ab. Unter anderem sicher davon, was man überhaupt als für die deutsche Sprache „fremd“ oder als in die deutsche Sprache „integriert“ betrachtet. Ich schließe mich Eisenbergs Standpunkt an: „Anglizismen sind nicht Wörter des Englischen, sondern sie sind Wörter des Deutschen. “21 Wenn man das ernst nimmt, kann die in der Kapitelüberschrift „Reichtum an Anglizismen - Armut der Sprache“ des eisenbergschen Beitrags enthaltende Frage eigentlich nur mit einem entschiedenen „Nein“ beantwortet werden. Wenn Anglizismen Wörter des Deutschen sind, kann ein Reichtum an ihnen nur eine Bereicherung des Deutschen sein, kein Dokument der Armut. Inwiefern nun sind Anglizismen Wörter des Deutschen? Weil sie außer in seltenen Fällen des „Zitatwortes“22 Eigenschaften des Deutschen annehmen, annehmen müssen, um ohne größere Probleme im Deutschen auf der lautlichen, der orthografischen, der morphologischen und der syntaktischen Ebene mitspielen zu können.

Dabei sind aus meiner Sicht die Probleme bei Aussprache und Schrift oft vergleichsweise größer als die in den beiden „höheren“ Ebenen. Und ich denke, sie sind auch diejenigen, mit denen sich nicht nur Sprecher und Schreiberinnen, die über keine oder geringe Englischkenntnisse verfügen, am ehesten schwertun und aufgrund derer sie Vorbehalte oder gar Ablehnung entwickeln. Statt geocaching, nach dem IDS-Neologismenwörterbuch ,Schnitzeljagd per GPS‘, wird gern auch geocashing geschrieben, und wie man es ausspricht - da gibt es viele Varianten. Soll man Soft Skills schreiben oder Soft-Skills oder Softskills usw. - es gibt rein rechnerisch 10 Varianten - wenn man über die weniger harten Eigenschaften im Berufsleben wie Sozialkompetenz und Teamfähigkeit reflektiert? In aller Regel werden Angloneologismen aber auch in Laut und Schrift an den so genannten ,Kernwortschatz“, also die in jeder Hinsicht „systemkonformen“ Wörter, herangeführt. Farm und Tram, beide um 1900 ins Deutsche entlehnt, werden heute meist mit einem Rachen-R und einem [a] ausgesprochen; sie klingen also ähnlich wie Farn bzw. wie der Anfang von Tram-polin und unterscheiden sich damit deutlich vom Original. $^{23}$

Wichtige Integrationsschritte sind bei Substantiven die Großschreibung und die Vergabe eines Genus. Dabei kann es zu Schwankungen kommen (die/das Email, die Tram und schweizerdeutsch: das Tram). Schließlich die Einordnung in eine Deklinationsklasse. Da bietet sich die Pluralbildung mit -s aufgrund der Analogie zum Englischen geradezu an. Wir haben sie in Kapitel 4 (Abschnitt 4.2) als 
die Pluralbildung für alles, was aus der Reihe tanzt, kennengelernt - Schmidts, LKWs, Uhus, Omas. Immerhin ist sie quantitativ bestens aufgestellt und wird von manchen als die Normal-Pluralbildung betrachtet. Auf der anderen Seite passen sich, eher selten, entlehnte Substantive auch in die anderen Typen systemgerecht ein: Es heißt die Farmen (nicht die ${ }^{\star}$ Farms), die Farmer (nicht die ${ }^{\star}$ Farmers), die Filme (nicht die ${ }^{\star} F i l m s$ ) und Gerhard Schröder wurde „Genosse der Bosse“ genannt.

Bei Verben ist die Einpassung in das Konjugationssystem unabdingbar. Bei den häufig einsilbigen einfachen englischen Verben ist es ein leichtes, sie mit den Verbaffixen zu versehen. Denkt man an chatten, mailen, leaken, liken, simsen oder twittern, so stellt man fest: „Keine einzige Form des deutschen Verbs stimmt vollständig mit der entsprechenden Form des Englischen überein, sofern es entsprechende Formen im Englischen überhaupt gibt. ${ }^{\text {24 }}$ Etwas schwieriger wird es bei komplexen Verben wie (to) download/upload oder (to) facebook, (to) whatsapp. Aber da gibt es durchaus vergleichbare Probleme mit eingeborenen Formen wie zwischenlagern, brandmarken oder wertschätzen. Wir kommen in Abschnitt 4.5 darauf zurück.

Zur Einpassung von Adjektiven gibt es verschiedene Strategien; man vergleiche: ein ganz tougher Junge, eine crazy Welt, ein fischiges Unternehmen (im Sinne von fishy ,anrüchig') oder fluffiges Brot (zu englisch fluffy, flaumig, locker').

Anglizismen sind also auf keinen Fall „Fremdwörter“. Allenfalls sind sie in bestimmten Aspekten anders als die landläufigen Wörter. Das kann sich mit der Zeit noch abschwächen oder gar ganz verloren gehen, wie etwa bei Star, Trick oder stoppen, die um 1900 schon in deutschen Texten vorkamen, oder schocken und toppen in der Bedeutung, überbieten“, die neueren Datums sind. Bei der hohen Entlehnungsfreundlichkeit spielt sicher die strukturelle Verwandtschaft zwischen dem Englischen und dem Deutschen eine Rolle. Diese besteht auf der lautlichen Ebene besonders auch zum Niederdeutschen (ebenso wie zum Niederländischen). So können wir in stoppen unschwer eine Variante des hochdeutschen stopfen erkennen, bei der wie auch im Niederdeutschen die Verschiebung von $p$ zu $p f$ nicht stattgefunden hat (vgl. dazu auch Kapitel 1).

Dass Anglizismen nicht unbedingt systemfremd sind und eine unverzichtbare Bereicherung des deutschen Wortschatzes darstellen, bedeutet nicht, dass ihr Gebrauch immer sinnvoll und angemessen ist. Zwar trifft es schon oft zu, dass vermeintliche Doubletten nicht wirklich gleichbedeutend sind. Ein Booklet ist kein Büchlein und auch Beiheft ist zu wenig spezifisch. Mit dem Anglizismus care wie in care work, gender care gap oder in den Hybriden Care-Berufe, Care-Arbeit ist nicht nur die Pflege gemeint, die etwa von Pflegediensten geleistet wird, sondern das gesamte professionelle oder private Tätigkeitsfeld des Pflegens, Für-andere-Sorgens und Sich-Kümmerns. Jemanden „daten“ ist nicht gleich mit ,sich mit jemandem treffen‘. Andererseits bleibt ein Bike allemal ein (Fahr-)Rad, auch 
wenn es vielleicht ein besonders sportliches oder aufgemotztes Modell ist, auf dem man bikt. Und ein Airport ist trotz internationalen Flugverkehrs nichts anderes als ein Flughafen. Statt von equipment zu sprechen, würde es in der Regel auch Ausstattung oder Ausrüstung tun. Statt bias empfiehlt sich gelegentlich das schöne Wort Schlagseite.

Die Übernahme von Wörtern aus anderen Sprachen ist aber keineswegs nur eine Einbahnstraße. Auch das Deutsche hat über die Jahrhunderte Elemente an andere Sprachen „ausgeliehen“. Bekannt sind Germanismen wie angst, übermensch (oder ubermensch) oder kindergarten, autobahn, bratwurst, schadenfreude oder zeitgeist, die Eingang ins Englische gefunden haben. Eine Munch-Ausstellung des Britischen Museums im Jahr 2019 beispielsweise trägt den Titel „Love and Angst“. Die in den 1930er Jahren oder während des Zweiten Weltkriegs entlehnte Vokabel blitzkrieg im Sinne von ,auf den Überraschungseffekt und schnellen Sieg ausgerichtete Militäroperation“ wird in Form der Abkürzung blitz jetzt auch auf jede Art „blitzschneller“ Aktion übertragen gebraucht. Es handelt sich dabei um Begriffe für Ereignisse oder Einrichtungen, deren „Erfindung“ Deutschland zugeschrieben wird, oder für als typisch deutsch erachtete Befindlichkeiten und Geisteshaltungen, aber auch um solche für mehr oder weniger bewunderte, belächelte oder kritisch beäugte zivilisatorische und kulinarische Spezialitäten. Aber wenn man genauer hinschaut, etwa bei der Lektüre englischsprachiger Romane, findet sich auch Kurioses wie etwa das im frühen 19. Jahrhundert entlehnte lammergeier (zu deutsch Lämmergeier) oder ganz und gar Unspektakuläres: Die Verben (to) spritz und (to) schlep(p) sind solche Beispiele. Beide wurden zu Beginn des 20. Jahrhunderts entlehnt; letzteres nicht direkt aus dem Deutschen, sondern aus dem Jiddischen, wo es bereits seit mittelhochdeutscher Zeit üblich war. Das Jiddische oder vielmehr Sprecher des Jiddischen dürften auch in vielen anderen Fällen (wie etwa (to) schmooze ,sich einschmeicheln` zu deutsch schmusen oder schnorrer wie deutsch Schnorrer ${ }^{25}$ oder auch shtick/ schtick ,Masche, Marotte‘ zu deutsch Stück) für die Einbürgerung von auf Varietäten des Deutschen zurückgehendem Wortschatz gesorgt haben, vor allem und zunächst im amerikanischen Englisch. Das Jiddische hat im Übrigen seinerseits auch das Deutsche bereichert mit Elementen meist hebräischen Ursprungs wie ausbaldowern, malochen, Schlamassel/vermasseln oder Chuzpe (englisch chutzpa). ${ }^{26}$

Auch im Französischen finden sich u. a. Wörter, die den Geist oder Ungeist deutscher Geschichte und Kultur widerspiegeln wie (le) Blitzkrieg, (le) Jugendstil, (le) Sturm und Drang, (le) Waldsterben, (la) Weltanschauung oder (le) Zeitgeist neben (le) bretzel oder (la) quenelle (,Knödel'). Wie man sieht, haben die ersteren in der Regel den Status von Zitatwörtern, erkennbar an Großschreibung und häufig auch der Setzung von Anführungszeichen.

Zahlreicher als ins Englische oder Französische sind die Entlehnungen in Sprachen in Mittel- und (Süd-)Osteuropa wie Polnisch, Rumänisch, Weißrussisch 
oder Ukrainisch und Ungarisch. Deutsch (bzw. dialektale Varietäten des Deutschen) war durch verschiedene Phasen der Kolonisation und Einwanderung seit dem Mittelalter in Regionen dieser Länder die Sprache oft zahlenmäßig großer, z. T. auch ökonomisch, kulturell und politisch dominanter Minderheiten und fungierte auch als Verkehrssprache, als lingua franca in einem vielsprachigen Kontext. Im Gefolge der Verbrechen gegenüber diesen Ländern in der Nazizeit und im Zweiten Weltkrieg hat sich die Lage völlig verändert. Deutschsprachige Minderheiten existieren nur noch in geringem Umfang, das Deutsche hat als Erstsprache wie auch im schulischen und universitären Kontext vermittelte und gepflegte Fremdsprache vergleichsweise geringen Stellenwert. ${ }^{27}$

Dennoch halten sich etwa im Polnischen eine ganze Reihe von deutschen Lehnwörtern. Das „Wörterbuch der deutschen Lehnwörter in der polnischen Schrift- und Standardsprache“ spricht von ca. 2500 deutschen Lehnwörtern, von denen allerdings 900 nur sporadisch belegt sind und offenbar nur kurzlebig in Gebrauch waren. Schon im 14./15. Jahrhundert wurden z. B. bursztyn ,Bernstein', burmistrz ,Bürgermeister', dach ,Dach', malować ,malen' und smakować ,schmecken‘ entlehnt, Ende des 18. Jahrhunderts urlop ,Urlaub‘, im 19. Jahrhundert klaps ,Klaps' und bumelować ,bummeln, nichts tun' ${ }^{28}$ Auch kindersztuba, platfus, szrot, szwindel, und sztambuch sind unschwer mit ihren deutschen Vorbildern Kinderstube, Plattfuß, Schrott, Schwindel und Stammbuch zu verbinden. ${ }^{29}$ Der Ausdruck wihajster (zurückgehend auf deutsch wie heißt er) wird eingesetzt, wenn einem das richtige Wort fehlt, steht also in etwa für ,der/die/das Dingsda'. (Englisch whatshisname wird speziell dann eingesetzt, wenn man den Namen einer Person nicht kennt.) Von den zahlreichen Übernahmen ins Ungarische seien beispielhaft diese genannt: ház ,Haus‘, lámpa ,Lampe‘, sonka ,Schinken', spájz ,Speisekammer'.

\section{Wortbildung: der kreative Umgang mit bereits existentem Material}

Es ist ausgeschlossen, hier einen Überblick über die Wortbildung des Deutschen samt einem Ausblick auf andere europäische Sprachen zu geben. Dazu ist dieses Feld zu weit. Ich versuche eher, an wenigen ausgewählten Phänomenen Charakteristisches herauszuarbeiten. Zunächst einmal ist klarzustellen: Wortbildung ist einerseits der Prozess der Erzeugung neuer Wörter aus altem Bestand. Wortbildungsprodukte wie verlegen, Ankunft, Motorradfan sind aber aus - länger oder kürzer - zurückliegenden Wortbildungsakten hervorgegangen und gehören heute ihrerseits zum festen Bestand. Sie wurden nach Regeln oder Mustern gebildet, die zum Teil heute nicht mehr ,produktiv` sind, wie etwa bei Ankunft zu an- 
kommen, oder aber solchen, mit deren Hilfe wir auch heute noch neue Wörter kreieren können wie im Fall von Elektrorollerfan oder auch Scooterfan, vielleicht nach dem Vorbild von Motorradfan. Wortbildung meint also neben dem jeweils aktuellen Prozess und seinen Produkten auch das generelle bzw. virtuelle Verfahren und seine Produkte.

\subsection{Ableitungen: die formale und semantische Kraft von Affixen}

Eine der beiden Hauptarten der Wortbildung im Deutschen wie auch in anderen europäischen Sprachen ist die Ableitung oder ,Derivation'. Genauer gesagt geht es hier um die ,explizite Derivation', bei der sprachliche Ausdrücke aneinanderfügt werden und nicht etwa nur eine Einheit lautlich oder in ihrer Kategorie verändert wird. Diese peripheren ,impliziten' Formen besprechen wir gegen Ende dieses Abschnitts. Die eigentliche Ableitung folgt einem einfachen Prinzip: Hänge an einen Wortstamm vorn oder hinten einen Nicht-Stamm und du erhältst einen abgeleiteten Stamm. Nennen wir dieses Prinzip die ,Affigierungsregel‘. Die einschlägige Art der NichtStämme, die Derivationsaffixe, besteht in unseren Sprachen aus einer überschaubaren Liste von Prä- und Suffixen. Sie machen aus einem einfachen lexikalischen Stamm einen abgeleiteten, und das Ganze kann sich in mehreren Schleifen wiederholen, indem der abgeleitete Stamm erneut abgeleitet wird, wie z. B. in

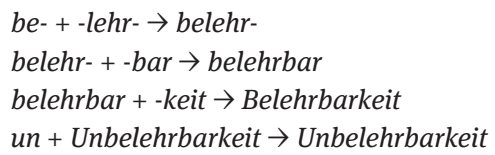

Die Affixe sind, was den „Input“ wie was den „Output“ angeht, kategorienspezifisch. Manche verbinden sich nur mit Elementen einer Wortart, manche auch mit denen mehrerer Wortarten. Das neue Wort gehört aber natürlich immer einer bestimmten Kategorie an. be- verbindet sich mit Verben (wie oben), aber auch mit Substantivstämmen (wie bei befrachten, belasten oder bemänteln) und mit Adjektivstämmen (wie bei befreien oder belustigen). Und, was herauskommt, ist immer ein Verb. -bar verbindet sich nur mit Verben, aber was herauskommt, ist ein Adjektiv. -keit wiederum will einen Adjektivstamm und erzeugt einen Substantivstamm. un- hingegen wird nicht nur einem Substantivstamm vorangestellt, sondern kann sich auch mit einem Adjektivstamm verbinden wie in unklug, unschön. Und Input und Output gehören hier jeweils zur selben Kategorie.

Ich greife nun die Bildung von Präfixverben wie belehren oder verlernen als beispielhaft für die Ableitung von Verben heraus. Für die Ableitung von Substantiven und Adjektiven konzentriere ich mich dann auf das Negationspräfix 
un- und sein Umfeld und gehe auch darauf ein, wie man ausgehend von Verben zu Substantiven für die entsprechenden Ereignisse und ihre Akteure kommt, also z. B. von lesen zu Lesung und Leser.

Bei der Ableitung von Verben spielen im Deutschen Präfixe die Hauptrolle. Im Zentrum stehen dabei diese: be-, ent-, er-, ver- und zer-. Die Präfixe sind grammatisch gegenüber dem Stamm der wirksamere Teil. Sie bestimmen nicht nur die Kategorie des Output-Worts, sondern auch dessen Valenz. be- z. B. erzeugt grundsätzlich transitive Verben, ganz egal, ob es sich mit einem Substantiv oder Adjektiv verbindet - man belastet, befreit oder belustigt ja jemanden - oder ob der Stamm ein intransitives Verb ist: Man belügt jemanden, während man einfach nur lügt. Die anderen Präfixe sind nicht ganz so eindeutig in Bezug auf Valenz. Da können auch intransitive Verben herauskommen: Ein Gedanke kann mir entfallen, eine Burg kann ver- oder gar zerfallen.

Worin besteht denn nun die inhaltliche Wirkung dieser Präfixe? Welchen Sinn hat Ableitung? Auf diese Fragen gibt es keine einfache Antwort: Die Bedeutung von Wortbildungsaffixen lässt sich nicht auf einen einfachen, einheitlichen Nenner bringen, gerade bei diesen uralten Verbpräfixen nicht. Sie stehen, anders als die Stämme, auf denen sie operieren, nicht für relativ klar hinsichtlich ihrer Merkmale bestimmbare Begriffe, denen man auch Gegenstände und Ereignisse zuordnen kann, die unter diese Begriffe fallen. Bei befrachten, bekleiden und belasten könnte die Bedeutung von be- hinauslaufen auf ein ,mit etwas Versehen'. Das funktioniert aber bei befreien oder belustigen nicht, sondern da geht es im Kern darum, jemanden frei bzw. lustig zu machen. Und bei verbaler Basis ändert sich meistens begrifflich gar nichts: Ein Belügen ist nach wie vor ein Lügen. Etwas klarer profilieren sich die Inhalte der Präfixe, wenn man sie miteinander kontrastiert. Wo be- ein Hinzufügen ist, ist ent- ein Wegnehmen; man vergleiche die Opposition von be- und entkleiden, von be- und entlasten usw. ver-ähnelt oft semantisch der Wirkung von be-; nur wird das Hinzugefügte noch vollständiger aufgetragen oder verteilt wie bei beschmieren versus verschmieren, beklecksen versus verklecksen usw. So können wir im folgenden Beleg die vorkommenden be-Verben durch die entsprechenden ver-Verben ersetzen: „Kurz darauf haben die fünf DarstellerInnen alle erreichbaren Oberflächen des vormals schwarzen Bühnenraums gründlich mit weißer Farbe bedeckt, bekleckst, beschmiert“ (die tageszeitung vom 17.10.2016). Das Resultat, nämlich Kurz darauf haben die fünf DarstellerInnen alle erreichbaren Oberflächen des vormals schwarzen Bühnenraums gründlich mit weißer Farbe verdeckt, verkleckst, verschmiert, ist soweit akzeptabel. Es zeigt aber auch, dass ver-Verben oft eine zusätzliche negative Komponente unterschiedlichster Spielarten haben: Wenn ich etwas verdecke, lasse ich meist keinen Zugang mehr dazu offen. Wenn ich etwas verkleckse oder verschmiere, entwerte ich es vielleicht. Wenn ein Mensch verspießert, eine Region verstädtert, also 
allmählich zum Spießer bzw. zur Stadt wird, ist das eher nicht zu begrüßen. ${ }^{30}$ Eine weitere dieser negativen Spielarten wird bei sich verfahren, sich vergaloppieren, sich verkalkulieren, sich verlaufen, sich verpokern, sich verschreiben, sich vertippen usw. aktiviert. Da fährt, galoppiert, kalkuliert, läuft, pokert, schreibt oder tippt man und macht dabei nur Fehler oder erreicht gar das Gegenteil des gewünschten Ziels. Dieses Muster ist übrigens auch heute noch produktiv, wird also aktiv für Neubildungen genutzt. Man kann sich ohne Weiteres heute verposten, also beim Posten einer Nachricht im Internet vertun, oder auch sich versimsen oder verwhatsappen - wie man sich schon länger bei dem Versuch, jemanden telefonisch zu erreichen, verwählen kann. Oder kann man es nicht auch ,sich verwählen“ nennen, wenn man die falsche Partei gewählt hat?

Diese semantische Wandlungsfähigkeit sorgt neben dem häufigen Verfügen über mehrere Valenzmuster dafür, dass Präfixverben, zumal die ver-Verben, besonders reich sind an unterschiedlichen Verwendungsweisen und Bedeutungen: verschreiben etwa hat neben dem erwähnten negativen reflexiven Gebrauch im Sinne von ,falsch schreiben` ein weiteres reflexives Muster, nämlich sich einer Sache verschreiben mit der Lesart ,sich ganz und gar einer Sache hingeben'. Das transitive etwas verschreiben wird gebraucht, wenn von der Verordnung von Medikamenten durch den Arzt die Rede ist.

In der reichen Palette von Präfixen zur Ableitung von Verben ähnelt das Deutsche unter unseren Vergleichssprachen am ehesten dem Polnischen. Allerdings ist deren wichtigste Aufgabe dort die Erzeugung eines perfektiven Gegenstücks zu einem imperfektiven Basisverb. Präfixe wie unter anderem po- mit pobiec zu biec ,laufen', za- mit zaczekać zu czekać ,warten', u- mit ugotować zu gotować ,kochen“ oder wy- mit wypić zu pić ,trinken' sind also wesentliche Elemente der Aspektkodierung. Und Aspekt spielt, wie wir in Kapitel 3 (Abschnitt 2.4) erfahren haben, im Deutschen keine Rolle. Aber die Präfixe fügen im Zuge der Perfektivierung oft auch eine neue Bedeutungsnuance hinzu. Zudem haben die Präfixe - es sind weit mehr als die genannten - oft auch eine lokale Bedeutung, wie etwa bei we- oder wy- in wejść ,hineingehen' und wyjść ,hinausgehen, ausgehen' zu iść ,gehen'.

Auch im Deutschen gibt es Präfixe, die „eigentlich“ lokale Präpositionen sind, wie durch in durch'schreiten, über in über'kleben, um- in um'fahren. Nicht von ungefähr habe ich hier eine Akzentmarkierung gesetzt. Denn daneben treten diese und weitere ähnliche Elemente auch als ,Verbpartikeln“ auf, ziehen dann den Akzent auf sich und verhalten sich so unorthodox, dass wir ihnen mit Abschnitt 4.5 besonderes Augenmerk widmen wollen. Hier nur ein Beispielpaar in direktem Kontrast: „Gesperrt sind ein Abschnitt der Bachstraße [...] sowie der Dorfplatz und der Rathausplatz. Der gesperrte Bereich kann aber um'fahren werden“ (Rhein-Zeitung vom 13.04.2018) gegenüber: „[...] und um ihre Kinder hat sie wegen der immer wieder ungesichert rückwärtsfahrenden Bau-Lastwagen Angst: 
"Wenn die jemanden 'umfahren, merken sie es nicht mal."“ (Frankfurter Rundschau vom 12.03.1997). ${ }^{31}$

Englisch verfügt zwar über eine Handvoll so genannter ,nativer Verbpräfixe‘, die mit der deutschen Gruppe verwandtschaftliche Ähnlichkeit haben. Im heutigen Englisch spielt aber allenfalls noch be- mit z. B. befriend (wörtlich ,befreunden'), besmoke (wörtlich ,berauchen') eine gewisse Rolle, während etwa das früher produktive fore- (wie z. B. mittelenglisch forespeak, foresay oder foretell) nur noch in meist archaisch klingenden Restbeständen überlebt, mit z. B. forego ,vorangehen', foreshadow ,auf Negatives vorausdeuten'.

Das Ungarische verfügt generell kaum oder gar nicht über Präfixe. Ableitung findet - und das in großem Umfang - praktisch nur über Suffigierung statt. Da gibt es im verbalen Bereich Suffixe, die nicht nur Modifikationen der Aktionsart und Aspektualität ausdrücken, sondern auch solche für Passivierung oder Reflexivierung, also Verfahren, die in anderen Vergleichssprachen durch syntaktische Konstruktionen ausgedrückt werden. Dazu gehört auch die Kausativierung mithilfe von -(t)at/-(t)et wie etwa bei járat, gehen lassen' (zu jár ,gehen') oder kerestet ,suchen lassen' (zu keres ,suchen').

Das Französische bietet die Gelegenheit, über Ableitungsmittel und -verfahren zu sprechen, die in hohem Maße auch das Englische, daneben das Deutsche sowie insgesamt wohl alle Sprachen betreffen, die wir im Blick haben: aus dem Lateinischen übernommene Elemente. Im Französischen und anderen romanischen Sprachen prägen diese die Wortbildung praktisch ausschließlich. Auf dem Weg ins Französische wurden z. B. lateinische Verbalpräfixe wie de- ,ab-, weg-‘ oder re- ,zurück, wieder' lautlich und in der Schrift angepasst. Dabei entstanden oft mehrere Varianten. Lateinisch de- tut sich offenbar zusammen mit dem lateinischen Negationspräfix dis- und kehrt wieder z. B. in descendre ,herabsteigen, aussteigen', aber auch in désarmer ,entwaffnen' oder déclasser ,deklassieren'. Lateinisch re- kann als re-, ré- oder ra- begegnen wie in recommencer, wiederbeginnen', réorganiser ,reorganisieren' oder rapporter ,zurückbringen‘. Zu allen genannten Verben gibt es Versionen im Englischen: to descend, to disarm, to declass, to recommence, to reorganise, to report. Und dies sind keine Einzelfälle: Das Englische hat nämlich - vergröbert gesagt - den Abbau germanischer Verbpräfixe (und anderer Wortbildungsaffixe) mehr als kompensiert durch die Übernahme von Affixen lateinischen Ursprungs, zunächst seit der normannischen Eroberung meist über das Französische, später auch direkt aus dem Lateinischen. ,Eurolatein‘, aber daneben auch Griechisch, ist auch im Deutschen das Fundament für den größten Teil unseres „Bildungswortschatzes“ und der Wissenschaftssprachen.

Auch im Deutschen sind die Bildungen mit den Präfixen de- und re- (wie deklassieren, demoralisieren; reaktivieren, regenerieren) unübersehbar zahlreich. Diese Verben weisen das im Bereich der eurolateinischen Wortbildung sehr produktive 
Verbalisierungssuffix -(is)ieren auf. Sie können dann weiter zu Substantiven abgeleitet werden und zwar z. B. mithilfe von -ung oder auch -(at)ion; man denke an Deklassierung, Demoralisierung, Reaktivierung, Regeneration. Neu war mir z. B. bis heute (30.12.2019) das Paar katastrophisieren - Katastrophisierung, das offenbar aus dem Vokabular der Psychotherapie stammt. ${ }^{32}$ Auch andere europäische Sprachen partizipieren an den eurolateinischen Wortbildungsmöglichkeiten. Polnisch etwa kennt demoralizować, ebenso wie reaktywować.

Bei der Ableitung von Elementen der nominalen Wortarten Substantiv und Adjektiv spielen im Deutschen Präfixe eine weniger große Rolle als beim Verb. Dafür sind die Elemente erz-, miss-, un- und ur- wie in Erzfeind oder erzkonservativ, Misserfolg oder missvergnügt, Unsinn oder unbequem, Urgeschichte oder urkomisch semantisch klarer profiliert als die oben genannten Verbpräfixe: erzund ur- drücken eine Steigerung in Bezug auf die zugeschriebenen Merkmale aus, wobei bei ur- das Anfängliche oder Unverfälschte entweder ganz im Vordergrund steht (Urahn, Urfaust) oder den relevanten Aspekt der Steigerung darstellt, wenn etwa von urbayrischen Brotzeiten als Inbegriff des Urgemütlichen die Rede ist. miss- und un- drücken Negation (in einem weiteren Sinne) aus. Das nicht sonderlich produktive Präfix miss- verkehrt einen Begriff nicht unbedingt in sein absolutes Gegenteil, sondern kann auch Verschlechterung, Zurückbleiben gegenüber dem Erwarteten oder Mangelhaftigkeit bezeichnen wie in Missernte, missverständlich.

In Verbindung mit Adjektiven wie klug, schön oder klar führt die Präfigierung von un- zu einem ,konträren` Gegensatz: Wenn etwas unklug, unschön oder unklar ist, ist es vielleicht nicht klug, schön oder klar. Es kann aber auch als weder klug / schön / klar noch als nicht klug / nicht schön / nicht klar gelten, also sich im weiten Feld der Abstufungen zwischen den Polen einer abstufbaren Eigenschaft befinden. Bei Adjektiven wie ungerade, ungiftig, unverheiratet oder (vielleicht auch ungrammatisch) - also nicht graduierbaren Adjektiven - führt un- zu einem ,kontradiktorischen' Gegensatz: Wenn Pilze ungiftig sind, dann sind sie schlicht nicht giftig, und man kann sie, so sie schmecken, essen.

Ist nun Unfreiheit der Zustand, unfrei zu sein, oder ist es das Gegenteil von Freiheit? Oder anders gesagt, läuft das Ganze so:

un- + frei $\rightarrow$ unfrei

unfrei + -heit $\rightarrow$ Unfreiheit

oder so:

frei + heit $\rightarrow$ Freiheit

un + Freiheit $\rightarrow$ Unfreiheit 
Im ersten Fall haben wir also die Struktur [[unfrei]heit], im zweiten die Struktur [un[freiheit]]. Bei der ersten Analyse wird zunächst das Adjektiv unfrei gebildet und dann das Substantivierungssuffix -heit angehängt; im zweiten Fall bilden wir gleich das Substantiv und präfigieren dann un-. Zwar neige ich spontan zur ersten als der semantisch natürlicheren Analyse; aber ausgeschlossen ist auch die zweite nicht. Anders dagegen z. B. bei: Unbändigkeit, Unpässlichkeit oder Unsäglichkeit. Hier ist die Analyse nach dem zweiten Muster auszuschließen, denn die Substantive ${ }^{*}$ Bändigkeit und ${ }^{*}$ Säglichkeit gibt es nicht, für Pässlichkeit gibt es zwar in DeReKo sechs Belege, aber die sind schon recht gekünstelt.

Ist die Basis jedoch ein Substantiv, kein Adjektiv wie in den Beispielen bisher, muss in aller Regel zuerst ein Adjektiv abgeleitet werden, das dann mit un- präfigiert wird, wie bei unabsichtlich, unfreundlich, unmenschlich, untätig. Macht man die un-Präfigierung als Erstes, kommen entweder Substantive heraus, die es gar nicht gibt wie (die) ${ }^{\star}$ Unabsicht, (der) ${ }^{\star}$ Unfreund oder wie bei Unmensch oder Untat Substantive, die semantisch nicht passen: Wenn man unmenschlich handelt, muss man kein Unmensch sein. Noch drastischer: Wer untätig ist, begeht nicht gleich eine Untat. Man vergleiche:

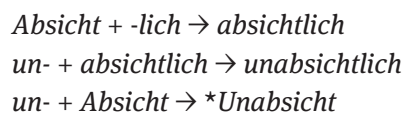

Das hängt auch damit zusammen, dass un- sich generell leichter mit Adjektiven als mit Substantiven verbindet. Aber wieder: Keine Regel ohne Ausnahme: unsinnig ist nicht das Gegenteil von sinnig, sondern hat die Lesart ,Unsinn enthaltend oder bedeutend'.

Englisch un-, aber auch polnisch nie- scheinen sich ähnlich wie das deutsche Präfix un- zu verhalten. Allerdings verbindet sich englisch un- kaum mit Substantiven (wie in unbelief, unease oder untruth), sondern es überwiegt noch stärker als im Deutschen die Präfigierung von Adjektiven. (Daneben kombiniert es sich auch mit Verbstämmen, wo es dann mit dem deutschen ,privativen', also ein Wegnehmen bedeutenden, Verbpräfix ent- korrespondiert wie in unload ,entladen'.) Auch hier ist man also in den meisten Fällen auf dem Holzweg, wenn man annimmt, zuerst verbinde sich un- mit einem Substantivstamm und dann werde daraus per Suffix ein Adjektiv gemacht. Einer dieser Holzwege führt von un + regret $\mathrm{zu}$ *unregret, womit die Ableitung von unregretful bereits blockiert wäre. Im Deutschen gibt es übrigens keine gute direkte Übersetzung für (un)regretful; wir weichen in der Regel von ??(un)bedauernd auf mit / ohne Bedauern aus. Zu polnisch dobry ,gut" gibt es die Negation niedobry, ungut, böse, schlecht‘ und zu chęć ,Lust, Neigung“ gibt es niechęć ,Unlust, Abneigung‘. Das Adjektiv chętny ,willig' ist zweifellos eine Ableitung aus chęć, und zwar mithilfe des Adjektivsuffixes - $n$-, wenn auch im Pol- 
nischen dort, wo ein Stamm und ein Suffix zusammenstoßen, oft eine Art Reibungsverlust entsteht und z. B. der Endrand verändert wird, ursprünglich wohl, um die Aussprache zu erleichtern. So stellt sich auch hier die Frage, ob niechętny ,unwillig, lustlos‘ zu verstehen ist als niechęć + ny oder als nie + chętny.

Vom Verb zum Substantiv führen im Deutschen wie in anderen europäischen Sprachen eine ganze Menge Ableitungswege. Eine zentrale Rolle spielen dabei im Deutschen die Suffixe -ung und -er: Mithilfe von -ung erzeugt man (abgesehen von isolierten Fällen) aus einem verbalen Prädikatsausdruck für Ereignisse einen substantivischen Prädikatsausdruck für Ereignisse: befragen wird z. B. gebraucht, um $\mathrm{zu}$ behaupten, dass es bestimmte Befragungs-Ereignisse gibt oder gab, während Befragung gebraucht wird, um auf die Klasse solcher Befragungsereignisse zu referieren. Man kontrastiere „Ein Betreiber großer Parkhäuser befragte seine Kunden nach ihren Lieblingsgerüchen“ (Hamburger Morgenpost vom 17.04.2009) mit „Die Befragung von Kunden durch einen Betreiber großer Parkhäuser erfolgte über das Internet“. Man kann transitive Verben - wie im Fall unserer Präfixverben - mit -ung überleiten in Befragung, Belehrung, Erziehung, Verkleidung, Zerstörung usw. oder prüfen in Prüfung, zähmen in Zähmung, kündigen in Kündigung, aber auch intransitive wie abbiegen in Abbiegung, landen in Landung, erblinden in Erblindung oder reflexive wie (sich) bewölken in Bewölkung. Auch bei dem nach wie vor produktiven Suffix ist jedoch nicht alles „erlaubt“: Ankommung z. B. ist blockiert durch Ankunft, Stürzung durch Sturz (allerdings nicht total, es gibt sieben Belege in DeReKo, sechs davon aus Wikipedia(-Diskussionen)). Zudem lassen sich anscheinend intransitive Dativverben wie jemandem danken, folgen, grollen oder helfen nicht mit -ung ableiten: Es gibt keine ${ }^{\star}$ Dankung, ${ }^{\star}$ Folgung, ${ }^{\star}$ Grollung ${ }^{\star}$ Helfung. ${ }^{33}$

Werden Verben nominalisiert, nehmen sie ihre Argumentstruktur mit, jedenfalls, was die semantische Seite angeht: Auch bei einer Befragung sehen wir eine Szene mit zwei Arten von Mitspielern vor dem geistigen Auge, Befragende (oder auch: Befrager bzw. Befragerinnen) und Befragte. Syntaktisch dagegen erfolgt notwendigerweise eine Umkodierung von Komplementen des Verbs zu Attributen des Substantivs, wie in dem Beispiel oben gezeigt. Wir haben dies in Kapitel 4 (Abschnitt 6.1) erläutert. Eines der Argumente kann auch als Erstglied bzw. Modifikator (vgl. dazu weiter unten) realisiert werden wie in Kundenbefragung, Kindererziehung. Liegen transitive Verben zugrunde, so wird deren Objekt-Argument, nicht das Subjekt-Argument in das Kompositum integriert: Elternerziehung hat nur die Lesart, dass Eltern erzogen werden, nicht die näherliegende, dass Eltern erziehen. Bei intransitiven Verben allerdings kann gelegentlich auch das Subjekt-Argument auftreten wie in Flugzeuglandung oder Arbeitnehmerhaftung. Einbindung in das Kompositum, also in ein Wort, bedeutet allerdings den Verlust der Referenzialität für den Modifikator: Nicht - wie bei Befragung der Kunden / Erziehung der Kinder bestimmte Kunden bzw. Kinder sind bei Kundenbefragung bzw. Kindererziehung im 
Blick. Es geht nur um Kunden und Kinder allgemein bzw. um den entsprechenden Begriff.

Noch etwas anderes geht verloren - eigentlich. Das Erstglied des Kompositums ist für syntaktische Prozesse wie die Attribuierung nicht mehr zugänglich. Hoffnung etwa erlaubt ein Attribut mit der Präposition auf wie in Hoffnung auf Frieden. Bei dem Kompositum Hoffnungsschimmer aber hat ein solches auf-Attribut nichts zu suchen - denn der Kopf, nämlich Schimmer, ist damit nicht kompatibel. Trotzdem finden sich z. B. für der letzte Hoffnungsschimmer auf Frieden Belege. Auch die Ansteckungsrate mit dem Corona-Virus ist eigentlich ein Unding, denn mit dem Corona-Virus gehört semantisch zum Erstglied Ansteckung, nicht zu Rate. Und ein Schild mit der Aufschrift Tragepflicht von Masken an einer Kaufhaustür irritiert mich. Allerdings kommt dieser „Fehler“ recht häufig vor. Zwar lachen wir über die reitende Artilleriekaserne oder der vierstöckige Hausbesitzer, aber weniger eklatante Dissonanzen nehmen wir unter Umständen hin. ${ }^{34}$

Nicht immer haben ung-Nominalisierungen - man hat für sie die lateinische Bezeichnung Nomina Actionis ,Tätigkeitsnomina“ - in konkreten Kontexten eine aktionale Lesart. In dem Beleg „Die Übergangsregierung in Bagdad verfügte die Schließung der Grenzen zu Jordanien und Syrien“ (Berliner Zeitung vom 09.11.2004) bezeichnet Schließung in der Tat einen Akt, eine Handlung. In anderen hingegen, z. B. dem Beleg „Der Betrieb ruht, an der Tür hängt ein Schild ,Heute geschlossen“. Doch die Schließung dauert ,ewig““ (Rhein-Zeitung vom 20.07.2000), ist der Zustand gemeint, der dem Akt des Schließens folgt. Zudem kann auch die Sache gemeint sein, die als Produkt aus entsprechenden Akten hervorgeht. Man vergleiche die beiden Vorkommen von Verkleidung: Die Kinder brauchten stundenlang für ihre Verkleidung versus Die Verkleidung stand ihnen gut.

Ableitungen auf -er sind zum einen Nomina Agentis ,Täterbezeichnungen'. So verwundert es nicht, dass Ableitungen auf -ung und auf -er oft paarweise auftreten: Erziehung - Erzieher, Forschung - Forscher, Planung - Planer. Aber es gibt zahlreiche Lücken, auf der einen wie auf der anderen Seite: Landung - *Lander, Bäcker ${ }^{*}$ Backung. er-Ableitungen sind besonders vertreten bei auf Verbstämmen basierenden Berufsbezeichnungen (Lehrer, Pfleger, Schneider). Aber auch dieses Suffix deckt weitere Felder ab. Man denke an die ebenfalls deverbalen Bezeichnungen für Instrumente oder Geräte, mit denen eine Handlung verrichtet wird oder die quasi selbst tätig werden wie Bohrer, Schraubenzieher, Wecker. Und so kann es auch hier zu mehreren Lesarten kommen wie etwa bei Ordner im Sinne von ,Person, die professionell ordnet' und ,Gegenstand / virtueller Ort für die Ordnung von Papieren bzw. Dateien‘. Schließlich kann man -er auch an Substantive anhängen, die Lehren, Theorien oder auch Institutionen bezeichnen, wie in Mystiker, Logiker, Banker, Schüler. So nennt man dann die (männlichen) Personen, die für eben jene Lehre 
oder Theorie stehen oder die in der einen oder anderen Weise mit der Institution befasst sind.

Nomina Actionis und Nomina Agentis spielen auch in anderen europäischen Sprachen eine besondere Rolle - handelt es sich doch um kognitiv wie kommunikativ zentrale Bezeichnungsweisen. Für sie stehen in vielen europäischen Sprachen neben „heimischen“ Suffixen (wie englisch -ing in upbringing ,Erziehung‘, healing ,Heilung‘ und -er in baker ,Bäcker‘, smoker ,Raucher‘ oder polnisch -anie/-enie in czytanie ,Lesung, ukojenie ,Linderung') auch die Nachfahren der lateinischen Suffixe -(at-)ion und -(at-)or bereit. Man vgl. deutsch und polnisch Organisation versus organizacja, Migration versus migracja - aus den polnischen Wörtern kann man unschwer das Suffix -acja isolieren - oder Organisator versus organizator, Agitator versus agitator, die das lateinische Suffix für Nomina Agentis unverändert fortführen. Auch im Ungarischen gibt es Bildungen auf -áció wie operáció sowie -or wie demonstrátor.

Die Verbpräfixe de- und re- sowie die nominalen Suffixe -(at)ion und -(at)or stehen für eine ganze Reihe von weiteren lateinischen (wie prä-, inter-, sub-; -abel/ibel, -ität) und griechischen (bzw. über das Gelehrtenlateinische auf das Griechische zurückgehende) Affixen (wie anti-, mega-, mikro; -ismus), die europäische Sprachen in unterschiedlichem Maße bereichern. Sei es, dass sie im Zusammenhang mit ganzen Lehnwörtern übernommen wurden, sei es, dass sie sich, wie das auch im Deutschen der Fall ist, selbstständig gemacht haben und produktiv in Wortneubildungen verwendet wurden. Man denke etwa an anti- ,gegen', das zunächst im Althochdeutschen in dem Wort Antichrist auftauchte und dann in zahlreiche Bildungen einging, von Antinomie und Antithese im 16. Jahrhundert bis antiautoritär und Antibabypille. ${ }^{35}$

Was übrig bleibt, wenn man aus solchen eurolateinischen oder auch eurogriechischen Wörtern das Suffix (und gegebenenfalls auch ein Präfix) abzieht, ist oft kein echtes Wort oder ein Wortstamm, an den man allenfalls Flexionsendungen anfügen müsste. agit-, das zum Beispiel bleibt, wenn wir die Suffixe -ation bzw. -ieren (für das Verb agitieren) abziehen, ist dann ein solcher Stamm, der nur „gebunden“ vorkommt. Oder denken wir an log- oder therm-, griechische Wortstämme, mit denen wir einiges anfangen können: von logisch über Logik, Logiker bis zu philologisch und logozentrisch bzw. thermisch, Thermik oder thermodynamisch. Nicht selten ist auch der Konsonant oder die Konsonantenverbindung am Ende eines solchen gebundenen Stammes nicht stabil, sondern veränderlich. So haben wir Inklusion, aber inkludieren, Konversion, aber konvertieren, Rektion/ Rektor aber regieren, inhärent aber Kohäsion. Das geht auf die lateinische Formenbildung zurück, die am Ende von Wortstämmen bei Flexion und Wortbildung systematische Veränderungen zuließ, ähnlich wie wir auch im Polnischen (vgl. chęć versus chętny) veränderliche Wortstammränder beobachtet haben. 
Wir können nun einige Merkmale der Derivation, wie sie nicht nur im Deutschen $\mathrm{zu}$ beobachten sind, festhalten: (1) Derivation scheint einer extrem vereinfachten Syntax zu folgen, nämlich der Affigierungsregel. (2) Bei mehrfacher Anwendung der Affigierungsregel können Strukturalternativen auftreten. Oft scheiden aber davon welche aus semantischen Gründen oder mangels der „Existenz“ eines in einem Zwischenschritt erzeugten Wortes aus. (3) Affixe und die zugehörigen Ableitungsmuster können mehr oder weniger produktiv sein. Aber auch bei Produktivität ist im Einzelfall nicht garantiert, dass ein so generiertes Wort im allgemeinen Wortschatz vorhanden oder gar usuell ist. (4) Ableitung führt aber trotz des Anscheins, einer simplen Syntax zu entsprechen, eindeutig zu Wörtern, nicht zu Syntagmen. Bei Wörtern ist sowohl auf der formalen wie auf der semantischen Seite mit mehr „Interaktion“ zwischen den beteiligten Einheiten und von daher mit mehr Irregularitäten zu rechnen. (5) Semantisch ist jedes Ableitungsmuster „volatil“.

Werfen wir noch einen Blick auf die ,implizite Derivation'. Da wird ohne Affixverbrauch allein durch offene oder verdeckte Manipulation an einem Wortstamm ein weiterer Wortstamm erzeugt. Im Deutschen ist da zum einen der Ablaut, den wir schon bei der Tempusbildung der starken Verben (in Kapitel 3, Abschnitt 2.5) kennengelernt haben. Er hat auch einen Platz als Form der impliziten Derivation, ist allerdings nicht mehr produktiv. So ist (das) Band durch Ablaut aus dem Verbalstamm bind- abgeleitet, (der) Fluss aus fließ-, (der) Riss aus reiß-, (der) Schub aus schieb-, (der) Fund aus find-, (das) Schloss aus schließ- usw. usw. Solche Paare aus Verb und durch Ablaut abgeleitetem Substantiv gab es auch in anderen germanischen Sprachen. Im Niederländischen sind auch heute noch Paare wie werpen versus worp (,werfen' versus ,Wurf') oder rijden versus rit (,reiten“ versus ,Ritt‘) existent, während das Englische die Ablaut-Komplikation zugunsten der Identität der beiden Wortstämme aufgegeben hat.

Diese zweite, auch ,Konversion“ genannte Form der impliziten Derivation ist im Englischen ganz massiv vertreten. Konvertiert werden nicht nur Verbstämme in Substantivstämme und umgekehrt - ganz besonders produktiv - Substantiv- in Verbstämme, sondern auch Adjektiv- in Verbstämme. Da kann aus dem Substantiv für einen Menschen einer bestimmten Profession oder mit einer bestimmten Rolle oder für eine Tiergattung wie butcher ,Schlachter', captain ,Kapitän', father ,Vater', witness ,Zeuge‘; ape ,Affe‘, fox ,Fuchs', snake ,Schlange‘ ein Verb werden, das typische Aktionsarten solcher Menschen oder Tiere bezeichnet: to butcher ,schlachten', to captain ,Mannschaftskapitän sein', to father ,Urheber sein', to witness ,bezeugen“; to ape ,nachäffen', to fox ,täuschen', to snake ,sich schlängeln'. Ebenso kann ein Werkzeug (Substantiv) mit der entsprechenden Tätigkeit (Verb) verpaart sein wie in hammer versus to hammer ,Hammer/hämmern' oder screw versus to screw ,Schraube/schrauben'. Der umgekehrte Weg vom Verb zum Substantiv verbindet 
z. B. eine Bewegung oder andere (körperliche) Aktion mit einer entsprechenden Bewegungs- oder - allgemeiner - Aktionseinheit wie bei to amble versus (an) amble ,schlendern/ein Schlendern', to crawl versus (a) crawl ,kriechen/ein Kriechen“, to run versus (a) run ,laufen/ein Lauf' to hit versus (a) hit ,schlagen/ein Schlag', to pull versus (a) pull ,ziehen/ein Zug', to scream versus (a) scream ,schreien/ein Schrei‘, to laugh versus (a) laugh, lachen/ein Lacher‘. Wenn Adjektive in Verben „verkehrt“ werden, geht es meist um ein Machen, seltener um ein Werden. Im ersten Fall entstehen transitive Verben wie bei to black,schwärzen“, to clean ,reinigen“, to empty ,leeren‘. Intransitive Verben nach dem zweiten Muster sind to pale ,erbleichen', to thin ,dünn werden'.

Vergleicht man hier mit dem Deutschen, so wird schon anhand der Übersetzungsäquivalente deutlich, dass auch im Deutschen Konversion möglich ist natürlich braucht das deutsche Verb eine Infinitivendung als Zitierform wie in schreien - Schrei, laufen - Lauf. Aber daneben gibt es vielfältige andere Möglichkeiten. So haben wir auch im Deutschen bei „Werkzeug-werkeln-Paaren“ neben Schraube - schrauben noch einige weitere Konvertierungen: Feile - feilen, Hacke - hacken, Schere - scheren. Hammer wird durch Umlautung zu hämmern, und in vielen Fällen wird umgekehrt aus einem Verb durch er-Ableitung die Bezeichnung für das Instrument oder Gerät wie in: Bohrer zu bohren, Mixer zu mixen, Roller zu rollen. Auf -er werden gelegentlich auch Substantive für kurze Aktionseinheiten abgeleitet wie bei (ein) Lacher, Schluchzer, Seufzer. Oft aber springt der substantivierte Infinitiv wie in (das) Schlendern, (das) Schluchzen hier ein. Wir können sogar verschiedene Komplemente an den Infinitiv anbinden und dann die gesamte „Verbalphrase“ in ein Substantiv konvertieren wie etwa bei „das permanente Sich-selbst-auf-die-Schulter-klopfen“ (Berliner Morgenpost vom 10.09.2008): Der nominalisierte Infinitiv ist ein für das Deutsche charakteristisches Konversions-Verfahren, bei dem andere Sprachen weniger mitmachen.

Beim Übergang vom Adjektiv zum transitiven Verb muss in der Regel, wenn überhaupt möglich, umgelautet werden wie in röten, säubern, schwärzen, töten. Intransitive Verben werden wie im Englischen durch Konversion erzeugt, z. B. grünen oder lahmen (versus transitivem lähmen). Oft kommt aber auch ein Präfix zum Einsatz: erblinden, ermatten, vereinsamen (intransitiv) oder befreien, begrünen, verdreifachen (transitiv), oder das Suffix -ig wie in festigen (zu fest), reinigen (zu rein) oder gar Präfix + Suffix + Umlaut wie in besänftigen (zu sanft).

Blicken wir noch einmal kursorisch auf die Möglichkeiten des Wechselns zwischen Wortarten im Englischen und Deutschen: Im Englischen kann das ohne jeden formalen Aufwand passieren. Der Reichtum gerade an einsilbigen Wörtern, die als Substantiv und Verb oder als Adjektiv und Verb gebraucht werden können, ist riesig. Demgegenüber sieht das Deutsche - das auch als „redselig“ bezeichnet wird - schwerfälliger und umständlicher aus. ${ }^{36}$ Vielleicht ist 
gerade diese „Einsilbigkeit“ und kategoriale Flexibilität, kurz die Ökonomie der Mittel, ein entscheidender Wettbewerbsvorteil für das Englische.

\subsection{Komposita zum einen: über mehrfache Schleifen, strukturelle Ambiguitäten und Fugenelemente}

Das Deutsche gilt als kompositionsfreudige Sprache. Davon zeugen nicht zuletzt die „Wortschönheiten“, die aus dem Grimmschen Wörterbuch zusammengetragen wurden, wie etwa: Augenlust, flatterschön, kohlpechrabenschwarz, Sonntagslangeweile, Zukunftsvorgefühl. ${ }^{37}$ Solche Wortschönheiten gefallen oft auch, weil sie selten vorkommen und von ausgeprägtem Sprachgefühl oder kreativer Sprachlust zeugen. Sie sind daher in aller Regel in dichterischer Sprache vorzufinden. Theodor Fontane etwa wird gerühmt für seine ,einzigartigen“ Wortneubildungen wie Ängstlichkeitsprovinz, Loyalitätsmäntelchen oder Schuhbürstenbackenbart. Ob diese und andere in seinen Werken jeweils nur einmal vorkommenden Komposita tatsächlich „Hapaxlegomena‘, also in einem repräsentativen Korpus nur einmal belegte Wörter sind, wäre allerdings noch nachzuweisen. ${ }^{38}$ Paul Celans Gedichtbände tragen Titel wie „Atemwende“, „Fadensonnen“, „Lichtzwang“ oder „Schneepart“ - Komposita, die eher verrätselt erscheinen.

Vor allem Substantive können also im Prinzip in einer Schleife unbeschränkt oft einer ähnlich einfachen Regel wie die Ableitungen folgen, der ,Kompositionsregel': Füge an einen Substantivstamm vorn einen weiteren Stamm (relativ) beliebiger Wortart an, und du erhältst einen Substantivstamm. So können wir den Substantivstamm Garten mit einem weiteren Substantivstamm erweitern zu Kurgarten oder Lustgarten, mit einem Adjektivstamm zu Kleingarten, mit einem Verbstamm zu Lehrgarten oder Irrgarten und auch mit einer Präposition zu Vorgarten. Bei Dauerkleingarten befinden wir uns bereits im zweiten Durchlauf: An das Kompositum Kleingarten wird vorn der Stamm dauer angefügt - es kann der Stamm des Verbs dauern sein oder aber der Stamm des Substantivs (die) Dauer. Der Substantivstamm Garten bleibt dabei semantisch wie formal die Hauptsache. Stets bezeichnet das Kompositum eine Art Garten, und nur der Bestandteil Garten wird (wie das Simplex) nach Kasus und Numerus flektiert; es heißt also z. B. des Kleingartens wie des Gartens und die Kleingärten wie die Gärten. Selbstverständlich sind auch alle diese Komposita wie Garten selbst Maskulina. Generell gilt: Der am weitesten rechts stehende Stamm bestimmt die Wortart und die morphologischen Eigenschaften eines Kompositums. Er ist der ,Kopf ' der Konstruktion und beeinflusst die Syntax des umgebenden Satzes wie der Kopf einer Nominalphrase. Der andere Bestandteil, das Erstglied, hat - vergleichbar den Attributen in der Nominalphrase den Status eines ,Modifikators‘. Traditionell heißt der Kopf eines Kompositums auch 
,Grundwort', der Modifikator ,Bestimmungswort', was dem semantischen Verhältnis der Teile in der Tat entspricht. Eher ausnahmsweise kann auch eine ganze Phrase als Erstglied auftreten wie etwa in Tante-Emma-Laden, Saure-Gurken-Zeit oder Geizist-geil-Verhalten. ${ }^{39}$

Komposita können - das bringt das Durchlaufen von Schleifen mit sich aus mehr als zwei Bestandteilen bestehen. Zum einen kann ein Stamm bereits abgeleitet sein wie etwa bei (das) Gärtchen, das dann z. B. in (das) Kleingärtchen eingehen kann, oder aber bei Lehrer (abgeleitet aus dem Verbstamm lehr-), das dann als Modifikator in Lehrergarten eingehen kann. Zum anderen kann es sich bei Kopf wie Modifikator um komponierte Stämme handeln wie eben in Dauerkleingarten - wo der Kopf das Kompositum Kleingarten ist, dessen Kopf wiederum das Simplex Garten ist - oder bei Heilkräutergarten - wo der Modifikator das Kompositum Heilkräuter ist. Immer wenn mehr als zwei Stämme im Spiel sind, kann es wieder zu Strukturambiguitäten kommen, ähnlich wie wir das bei komplexen Ableitungen gesehen haben. So plädiere ich bei Bundesverfassungsgericht und Staatssicherheitsgericht jeweils für die Struktur a) gegenüber der weniger plausiblen Struktur b):
a) Bund(es) + Verfassungsgericht
b) Bundesverfassung(s) + Gericht
a) Staatssicherheit(s) + Gericht
b) Staat $(s)+$ Sicherheitsgericht

Das Bundesverfassungsgericht ist das Verfassungsgericht des Bundes, im Gegensatz zu den einzelnen Landesverfassungsgerichten (nicht: ein Gericht für die Bundesverfassung). Dagegen ist ein Staatssicherheitsgericht, wie es das z. B. in der Türkei geben soll, ein Gericht, das für die Staatssicherheit zuständig ist (nicht: ein Sicherheitsgericht für den Staat). Und Fontanes Schuhbürstenbackenbart ist ein Backenbart, der einer Schuhbürste ähnelt, besteht also ganz symmetrisch aus zwei ihrerseits zweiteiligen Komposita: [[Schuhbürste(n)][backe(n)bart]]. Wir kommen nicht auf die Idee, z. B. hier einen Bürstenbackenbart für Schuhe zu erkennen, also so zu teilen: [[Schuh][[bürste(n)][backe(n)bart]]]. Bei dem von der SPD in die Diskussion gebrachten „Windbürgergeld“ hingegen werden wir eher so teilen: [[Wind][Bürgergeld]], wollen wir doch nicht annehmen, dass es Windbürger ähnlich wie Wutbürger - gibt. ${ }^{40}$

Da könnte ja vielleicht die Betonung die beiden Strukturen - und mit ihnen die Lesarten - auseinanderhalten. Bei einfachen Komposita aus zwei Bestandteilen wie Verfassungsgericht oder Bürgergeld wird immer der erste Teil, der Modifikator, betont. Das ist inhaltlich einleuchtend, liefert doch der Modifikator die Spezifikation, die einen allgemeineren Begriff eingrenzt, also z. B. Verfassungsgerichte von Amtsgerichten oder ein Bürgergeld von einem Schweigegeld unterscheidet. Bei Komposita mit drei Bestandteilen wird nun aber erst einmal nach prosodischen Gesichtspunkten betont, und zwar wird der Bestandteil hervorgehoben, der „schwe- 
rer“ ist, in dem Sinne, dass er sich in zwei morphologische Bestandteile verzweigt. Dessen wiederum erster Bestandteil ist dann der Akzentträger. Wir haben also nach der jeweils präferierten Struktur so zu betonen: Bundesver'fassungsgericht, Wind'bürgergeld. Beim Bundesverfassungsgericht halten wir uns, denke ich, daran. Obwohl: Eigentlich wäre es semantisch angemessener, auch hier den entscheidenden Unterschied durch Betonung hervorzuheben und dadurch dieses höchste Verfassungsgericht von den Landesverfassungsgerichten abzugrenzen. So wird denn in der Praxis, wenn die Struktur uns vertraut oder klar ist, von der prosodischen Regel oft abgewichen und auch bei „rechtsverzweigender“ Struktur der linke, nicht verzweigende Bestandteil betont. Sagen wir nun also doch: 'Windbürgergeld? ${ }^{41}$

Bisher haben wir bei der Zerlegung von Komposita stillschweigend „,zusätzliches“, nicht zu den jeweiligen Stämmen gehörendes, Material an der „Fuge“ zwischen den Bestandteilen in Klammern gesetzt, also quasi ignoriert. Was hat es mit -(e)s- in Bundesverfassungsgericht, Meeresrauschen oder dem -(e)n- in Schuhbürstenbackenbart oder Menschenbild, mit -er- in Rinderbraten oder auch dem - - - in Schweinegeld auf sich? Man hat sie, im Falle von - $(e) s-$, als Genitiv- oder, im Falle von -(e)n-, -er- oder - $e$-, als Pluralmarkierung des vorausgehenden Stammes betrachtet oder zumindest jeweils darin den Ursprung für die weite Ausbreitung der Marker auf Stämme gesehen, die eine solche Genitiv- oder Pluralbildung gar nicht kennen. ${ }^{42}$

Denn einerseits gilt: Die Form Gerichts in Gerichtsbeschluss etwa ist identisch mit der regulären Genitivform von Gericht. Man sagt dann auch, das -s sei „paradigmisch“, gehört es doch in das Flexionsparadigma des Wortes. Einigermaßen plausibel wird die Idee dadurch, dass im „älteren“ Deutsch Genitivattribute generell dem Kopf vorangestellt werden konnten, sodass von eines Gerichts Beschluss nur zwei, drei kleine Schritte nötig waren, um zu eines Gerichtsbeschluss(es) zu gelangen: die Fusion von Gerichts und Beschluss zu einem Wort, ggf. die „Umwidmung“ des indefiniten Artikels auf das neue Kompositum und ggf. die Genitivmarkierung am neuen Wortende. Oder um es mit Klammerung auszudrücken: von [[eines Gerichts] Beschluss] zu [eines Gerichtsbeschluss(es)]. Nun gilt aber weder: Alle Substantive mit Genitiv-(e)s haben eine $s$-Fuge. Noch gar: Nur Substantive mit Genitiv-(e)s haben eine s-Fuge. Dem erstgenannten „Gesetz“ widersprechen z. B. die Maskulina auf -er, die in aller Regel die Fuge leer lassen wie in Lehrerzimmer, Hamsterrad. Dem zweiten „Gesetz“ widerspricht beispielsweise das Wort Bundesverfassung. Es ist ein Femininum und kennt kein -s im Genitiv. Das -s am Ende von Bundesverfassungs- in Bundesverfassungsgericht und in der Mehrzahl aller Wörter mit $s$-Fuge ist also nicht paradigmisch. Dass beim Gros der Komposita mit (e)s-Fuge diese nicht-paradigmisch ist, ergibt sich schon daraus, dass die hochfrequenten Ableitungssuffixe für (nicht-personale) Feminina, nämlich -ion (vgl. Koalitionsver- 
trag), -ität (vgl. Identitätspolitik), -heit (vgl. Vergangenheitsbewältigung), -keit (vgl. Fruchtbarkeitsgöttin), -schaft (vgl. Gesellschaftsvertrag) und -ung (vgl. Lösungsweg) grundsätzlich eine $s$-Fuge fordern. Als Kuriosum sei vermerkt, dass im deutschen Steuerwesen konsequent das Fugen-s bei der Benennung der Steuerarten vermieden wird: Einkommensteuer Körperschaftsteuer, Erbschaftsteuer, Schenkungsteuer, Grunderwerbsteuer. Wir Steuerzahler allerdings tendieren in all diesen Fällen zur $s$-Fuge - schließlich nehmen wir Einkommenseinbußen in Kauf und schließen Schenkungsverträge ab, und auch der Duden lässt diese Steuer-Varianten zu.

Was -(e)n angeht, so haben die (personalen bzw. belebten) schwachen Maskulina in aller Regel eine (e)n-Fuge wie in Affenzahn, Botenstoff, darunter auch die Personenbezeichnungen mit den aus dem Gräkolateinischen entlehnten Suffixen -ant (vgl. Demonstrantenzug), -ent (vgl. Studentenfutter), -ist (vgl. Nudistencamp). -(at)or (vgl. Rektorenkonferenz, Moderatorenrolle). Das -(e)n ist hier paradigmisch und könnte als Pluralmarker verstanden werden. Auch viele Feminina mit $(e) n$ Plural haben eine entsprechende - paradigmische - Fuge wie in Frauenzimmer, Schwesternschule, Geburtenkontrolle. Aber daneben gibt es auch viele auf Konsonant endende Simplex-Feminina, die trotz en-Plural die Fuge leer lassen, man denke z. B. an die Komposita mit Erstglied Tür (Türangel, Türgriff, Türöffner) aber z. B. Türenhersteller. Die Feminina auf auslautendes -e (gesprochen: Schwa) hingegen tendieren, wie wir schon bei Bürste oder Backe gesehen haben, stark zur (e)n-Fuge, wobei Linguisten darüber streiten, ob das Schwa Teil des Stamms oder der Fuge ist.

Kurz gesagt: Es existiert keine einfache Regel für das Schicksal der Fuge. Vielmehr gibt es eine ganze Reihe von unterschiedlich starken und z. T. einander überlagernden Prinzipien, die die Gestalt der Fuge prognostizieren. Man kann sie in komplexen Entscheidungsbäumen strukturieren, die allerdings nur in seltenen Fällen eindeutig deterministische Kraft haben. ${ }^{43}$ Das zeigt schon das Nebeneinander von mehreren Fugen bei ein- und demselben Erstglied wie etwa in Tagtraum, Tageslicht, Tagedieb. ${ }^{44}$ Was in solchen Entscheidungsbäumen für eine automatisierte Analyse (bisher) nicht berücksichtigt wird, ist der Einfluss semantischer Faktoren. So tritt das Substantiv Mord als expressiv-verstärkendes Erstglied immer mit $s$-Fuge auf wie in Mordsangst, Mordsgaudi, Mordshunger, während es in seiner „normalen“ Bedeutung fugenlos vorangestellt wird: Mordfall, Mordversuch.

Einen recht starken solchen Faktor möchte ich hier unter Vorgriff auf eine detailliertere Erörterung der Semantik der Komposition nennen: den „gleichberechtigten“ Status des Erstglieds anstelle des üblichen „untergeordneten“ Status. Hier bleibt in der Regel die Fuge leer. Man denke an Kindfrau neben Kindeswohl und zahlreichen anderen Bildungen mit es-Fuge sowie Kinderfrau und zahlreichen anderen mit der Pluralform. Oder auch Fürstbischof (z. B. neben Fürstengruft), Gottkönig (z. B. neben Gottesfurcht und Götterglaube), Mannweib (z. B. neben Mannes- 
kraft und Männerbund) oder Prinzgemahl (neben z. B. Prinzenpalais). Die Erstglieder sind hier jeweils insofern eher gleichberechtigt, als sie Eigenschaften oder Merkmale nennen, die ebenso auf einen virtuellen Referenten zutreffen müssen wie die mit dem Zweitglied genannten: Eine Kindfrau ist ein Wesen, das gleichermaßen als Kind wie als Frau erscheint, ein Fürstbischof einer, der sowohl Fürst als auch Bischof ist. Ein Bürgerjournalist - eine Neubildung, mit der die Tätigkeit von Bloggern wohlwollend umschrieben wird - agiert gleichermaßen als Bürger wie als Journalist. Ähnlich auch der Bürgerforscher oder die Bürgerforscherin, in welchem Fall Bürger und Bürgerinnen sich gleichzeitig als Forscher betätigen. Allerdings ist bei Erstgliedern mit einer paradigmisch stark favorisierten $(e) n$-Fuge dieses formale Prinzip stärker als die semantische Eigenschaft ,Kopulativkomposita', wie etwa bei Hosenrock (etwas, das Rock und Hose zugleich ist oder zu sein scheint) oder Waisenkind (zugleich Waise und Kind). Hinzu kommt, dass die semantische Kategorie selbst ein ziemlich unsicherer Kandidat ist: Kann man nicht auch einen Hosenrock primär als einen Rock verstehen, der nur Ähnlichkeiten mit einer Hose hat - im Gegensatz zu einer Rockhose, was dann eine Hose wäre, die einem Rock ähnelt? In diesem Fall läge dann doch eine Unterordnungsrelation vor, wie bei den gewöhnlichen ,Determinativkomposita ‘ ${ }^{45}$

Neben den Substantiven sind auch die kategorial verwandten Adjektive im Deutschen vergleichsweise kompositionsfreudig. Zwar verbinden sich adjektivische Köpfe in allererster Linie mit Substantiven und Adjektiven als Erstglieder wie etwa in flaschengrün oder blaugrün. Aber auch Verben und gelegentlich Adverbien oder Präpositionen sind als Modifikatoren möglich wie in schreibfaul, lesefähig, redewillig (und ähnlich wie in schreibfähig, lesekundig usw.), immergrün, übereifrig, überkorrekt, vorschnell, vorlaut oder unterkomplex. Allerdings muss bei den Adjektiven, die auf ein adjektivisches Suffix wie -ig oder -lich enden, stets bedacht und geprüft werden, ob wir es nicht „eigentlich“ mit der Ableitung aus einem Substantiv zu tun haben. So ist hinterlistig als ,voll Hinterlist“ zu interpretieren, nicht als Zusammensetzung aus der Präposition hinter und dem Adjektiv listig oder vorfreudig als, voller Vorfreude' und nicht als Kompositum aus vor + freudig komponiert. Bei übereifrig mag man schwanken zwischen der Zuordnung zum Substantiv Übereifer und der Analyse als über + eifrig. über wird ja auch bei anderen Adjektiven, etwa übergenau oder überkandidelt für norm“überschreitende“ Eigenschaften verwendet. Allerdings lassen sich Adjektive im Unterschied zu Substantiven kaum auf einen oder gar mehr Zyklen der Zusammensetzung ein: immerflaschengrün oder dauerleseunfähig würden wir allenfalls experimentell bilden.

Auch in zusammengesetzten Adjektiven kann sich ein Fugenelement einnisten wie in lebenstüchtig, publikumswirksam, rabenschwarz, göttergleich eine weitere Bestätigung für die Nähe der beiden nominalen Wortarten. Auch 
der Vokal -o- ist sowohl bei Substantiven als auch bei Adjektiven als Fugenelement im Gebrauch, sofern mindestens einer der beiden Bestandteile - in aller Regel ist dies ein nur gebunden vorkommender Stamm - aus dem Lateinischen und vor allem dem Griechischen entlehnt ist: Thermodynamik, Soziolinguistik versus anglophil, frankophon. Dieses Fugenelement wird, eher spielerisch, auch eingesetzt, wenn das Erstglied nicht aus den klassischen Sprachen entlehnt ist, wie etwa in Bonzokratie, Filzokratie, Tütophobie. ${ }^{46}$ Ähnlich wie die Stämme selbst ist auch das auf das Altgriechische zurückgehende Fugen-o- ein sprachübergreifendes Erbe. Meritokratie und seine Ableitung meritokratisch etwa haben Entsprechungen in englisch meritocracy/meritocratic, französisch méritocatie/ méritocratique, polnisch merytokracja/merytokratyczny und ungarisch meritokrácia/meritokratikus. Im Polnischen übrigens, wo Komposition eine vergleichsweise geringere Rolle spielt, ist die -o-Fuge das Mittel der Verbindung in substantivischen und adjektivischen Komposita, weit über entlehnte Stämme hinaus So bei Substantiven wie in śrubokręt ,Schraubenzieher' (zu śruba ,Schraube und kręt ,Drall, Drehbewegung', zu kręcić ,drehen') oder zlewozmywak ,Waschbecken` (zu zlew ,Becken' und zmywak ,Spüle') und bei Adjektiven wie szaroniebieski ,graublau‘ (zu szar-y ,grau' und niebiesk-i ,blau') oder wysokogatunkowy ,edel' (zu wysok-i ,groß` und gatunkow-y, nach bestimmter Art, spezifisch').

\subsection{Komposita zum anderen: Vielfalt oder Einheit der Bedeutung}

Hervorstechendes Merkmal der Komposition ist die Ökonomie der Mittel. Wenn Wortstämme einfach - mit oder ohne Fuge - aneinandergereiht werden, bleibt aber, so scheint es, Entscheidendes ungesagt: Worin besteht die Relation zwischen Hut und Schachtel in Hutschachtel? Es handelt sich doch wohl nicht um „dieselbe“ wie zwischen Hut und Fabrik in Hutfabrik. Und wie steht es bei Holzschachtel gegenüber Holzfabrik, ganz zu schweigen von Krawallschachtel oder Bildungsfabrik? Linguisten haben bei der semantischen Analyse von Komposita - sie haben dabei vor allem Substantiv-Substantiv-Komposita im Visier - im Prinzip die Wahl zwischen zwei Ansätzen: einem interpretationistischen und einem reduktionistischen. Beim interpretationistischen Ansatz geht man von einer Vielfalt inhaltlicher Beziehungen aus, nach Maßgabe der in Wörterbüchern festgeschriebenen oder allgemein naheliegenden Interpretation der Beziehung zwischen den Teilen. Ältere Standardwerke der Wortbildungslehre vertreten eher einen interpretationistischen Ansatz. Dabei wird oft die Bedeutung von Komposita durch zugrundeliegende Sätze zu erfassen gesucht. So führt Marchand die Bedeutung von steamboat auf den Satz ,steam powers, operates the boat' zurück, die von arrowhead auf, the arrow has a head'. Analog kann man bei deutsch Dampfschiff beziehungsweise Pfeil- 
spitze verfahren. ${ }^{47}$ Ortner et al. geben Paraphrasen an wie etwa ,Dreieck, das aus Gleisen gebildet wird“ für Gleisdreieck. ${ }^{48}$

Beim reduktionistischen Ansatz hingegen, der in verschiedenen Varianten neuerdings dominiert, sieht man den Inhalt ähnlich ökonomisch wie die Form, nach dem Motto: Wo es formal nur eine asymmetrische Beziehung zwischen zwei Bestandteilen gibt, nämlich ein Vorher-Nachher, gibt es entsprechend auch nur eine einzige asymmetrische inhaltliche Beziehung.

Schauen wir etwas genauer auf den reduktionistischen Ansatz: Da wird die formale Beziehung zwischen Kopf und Modifikator konsequent auf die Inhaltsseite übertragen, und zwar als eine Relation der näheren Bestimmung (welcher Art auch immer) des durch den Kopf bezeichneten Begriffs durch den durch den Modifikator bezeichneten Begriff. So haben es bereits Grammatiker wie Wilhelm Wilmanns oder Hermann Paul um die Wende vom 19. zum 20. Jahrhundert gesehen. Wilmanns etwa argumentiert, dass die Komposition „immer nur die Verbindung im allgemeinen“ ausdrücke. ${ }^{49}$ Oder anhand von Beispielen gesagt: Eine Hutschachtel ist dann also eine Schachtel, die in Verbindung steht mit Hüten (oder auch mit dem Begriff ,Hut'), wie auch eine Hutfabrik eine Fabrik ist, die etwas mit Hüten (oder dem Begriff ,Hut') zu tun hat usw. Worin die Verbindung oder das „Miteinander-zu-tun-Haben“ besteht, bleibt offen. Die konkrete Interpretation wird hier als Sache eines verfestigten Sprachgebrauchs oder auch als Sache unseres Wissens betrachtet und nicht der sprachlichen Bedeutungsseite im engeren Sinne zugerechnet. So deuten wir Hutschachtel in der Regel als ,Schachtel für die Aufbewahrung eines Hutes oder von Hüten', weil Schachteln eben die Funktion von Verwahrorten oder Behältnissen haben. Und wir deuten Hutfabrik üblicherweise als ,Fabrik, in der Hüte hergestellt werden', weil Fabriken eben Produktionsstätten sind. Nichts hindert uns aber - so argumentieren die Reduktionisten - Hutschachtel, wenn der Zusammenhang es erlaubt, auch z. B. zu verwenden und zu deuten als, Schachtel, die Ähnlichkeit mit einem Hut hat‘ oder in Anlehnung an das übliche Verständnis von Holzschachtel und mit etwas Fantasie als ,Schachtel, die aus einem Hut hergestellt wurde‘.

Für den reduktionistischen Ansatz sind Determinativkomposita das Maß aller Dinge. Bei ihnen bezeichnet der Kopf einen Begriff, der durch den Modifikator auf einen Unterbegriff eingeschränkt wird. In welcher Weise dies dem Unterbegriff gelingt, ist im Prinzip semantisch unerheblich. Naheliegend ist es aber, dabei gegebenenfalls auf die inhärente Relationalität der Teile zurückzugreifen und, sollte eine solche nicht vorliegen, auf die Wortbedeutungen der Teile sowie naheliegende allgemeinere Typen von Begriffs-Verhältnissen, die bei der (Sub-)Klassifikation eine Rolle spielen. Inhärente Relationalität von Wörtern ist ein sprachübergreifendes Phänomen. Der relationierende Rückgriff auf Wortbedeutungen und vor allem die Stiftung passender Begriffs-Verhältnisse ohne zwingende 
Basis in Wortbedeutungen sind konzeptuell, also in Wahrnehmung und schlussfolgerndem Denken verankerte Verfahren und damit ebenfalls weitgehend sprachübergreifend. Daher sind starke Parallelen zwischen Sprachen, die über den Typ der Determinativkomposita verfügen, zu vermuten. Unter unseren Sprachen sind hier vor allem das Englische und das Ungarische zu nennen. Ich werde daher deutschen Beispielen für die verschiedenen Typen gelegentlich auch englische und ungarische zur Seite stellen. Das bedeutet jedoch nicht, dass im Einzelfall dasselbe Verfahren angewandt wird. Denn in vielen Fällen lässt sich die gewünschte Beschränkung eines Begriffs schlussfolgernd herleiten durch unterschiedliche spezifizierende Relationen zu verschiedenen Begriffen, die als Modifikator dienen können. So steht neben deutsch Blindenhund (also ,Hund für Blinde') das englische guide dog, wörtlich ,Führhund‘.

Die erste Möglichkeit, die gegebenenfalls vorhandene inhärente Relationalität des Kopfs, nutzen wir in der Regel bei Komposita wie Fahrradkauf, Kuchenbäcker oder Bankierstochter: Da geht es um eine Aktion, bei der ein Fahrrad oder Fahrräder gekauft werden bzw. um einen Akteur, der professionell Kuchen backt bzw. um die Tochter eines Bankiers. Nicht immer aber muss oder kann so interpretiert werden: Ein Zuckerbäcker ist eher einer, der mit Zucker (etwas) backt und eine Filmtochter ist eine Person, die in einem Film die Tochter einer anderen Person spielt. Ist der Modifikator ein Verb- oder Adjektivstamm, so kann dieser in einem ersten Zugriff - als Prädikat über das vom Kopf Bezeichnete verstanden werden: Eine Schwebebahn ist eine Bahn, die schwebt, eine Hängebrücke eine Brücke, die hängt, ein Weichkäse ein Käse, der weich ist, Sauerkraut ist Kraut, das sauer schmeckt. Aber diese Beispiele zeigen: Die Prädikat-Argument-Relation ist nur ein Hilfsmittel, ein konzeptueller Anhaltspunkt zum Zweck der Subklassifikation, also etwa zur Unterscheidung von verschiedenen Konstruktionstypen für Brücken oder Bahnen beziehungsweise Arten von Käse oder Kraut. Sie darf nicht als aktual wahre Aussage gewertet werden: Schwebebahnen schweben nicht immer, auch Weichkäse können gelegentlich hart werden, und manche bereiten Sauerkraut recht süßlich zu.

Im Defaultfall, also wenn der Kopf (bzw. eingeschränkter auch der Modifikator) nicht relational ist oder nicht relational interpretiert werden kann oder soll, sind wir, wie gesagt, auf die (sortalen, also nicht-relationalen) Wortbedeutungen im Verbund mit generellen Verfahren der Subklassifikation zurückgeworfen. Diese bestehen im Wesentlichen im Rückgriff

- auf situierende Relationen, bei denen Kopf oder Modifikator als Ort oder Zeit interpretiert werden, an dem mit dem vom jeweils anderen Begriff Bezeichneten etwas passiert: Teehaus ,Haus, in dem vorwiegend Tee serviert wird' (vgl. englisch tearoom, ungarisch teaház), Tischleuchte ,Leuchte, die auf einen Tisch gestellt wird“(englisch table lamp), Uferschwalbe ,Schwalbe, 
deren Habitat die Uferregion ist‘, Sonntagsbraten ,Braten, der für den Verzehr am Sonntag bestimmt ist', Ballabend,Abend, an dem ein Ball gegeben wird', Nachteule ,jemand, der gerne bis spät in die Nacht hinein aufbleibt‘ (englisch night owl);

- auf konstitutive Relationen, bei denen der Kopf als Teil dessen interpretiert wird, was unter den vom Modifikator bezeichneten Begriff fällt (Tischbein, engl. table-leg) oder als Gegenstand, der aus dem vom Modifikator bezeichneten Material besteht (Holzbein), bzw. der das vom Modifikator bezeichnete Material als wesentlichen Bestandteil enthält (Käsekuchen, englisch cheese cake, ungarisch sajttorta (,Käse' + ,Kuchen'));

- auf funktionale Relationen, bei denen der Modifikator (typischerweise ein Verbstamm) den Zweck oder die Funktion nennt, die mit dem vom Kopf Bezeichneten verfolgt oder ermöglicht werden soll: Schreibtisch (englisch writing desk), Leselampe (ungarisch olvasólampa (,Leser/lesend“ +,Lampe')). Oder aber der Modifikator nennt einen Gegenstand, der die mit dem Kopf verbundene Funktion näher spezifiziert. In diesem Fall geht man von der mit der Wortbedeutung des Kopfes gegebenen Funktionsbestimmung aus, etwa nach folgender Schlussfolgerung für Holzfabrik, Fabriken dienen der Herstellung von etwas, hier also von Holz' oder für Milchglas in einer der möglichen Lesarten ,ein Glas dient als Behältnis, aus dem Flüssigkeiten getrunken werden können, hier dann Milch`. Oder für Rheinbrücke: ,Brücken haben die Funktion, eine Verkehrsverbindung über ein Hindernis hinweg herzustellen, hier also über den Fluss Rhein'. Funktionen müssen aber nicht unbedingt bedeutungsmäßig fest verankert sein, sie können sich auch aus unserem stereotypischen Sachwissen ergeben. Ein Blindenhund z. B. ist ein Hund, der die Aufgabe hat, Blinde zu führen;

- auf Zugehörigkeitsrelationen, bei denen der Modifikator die Person, Sache oder Institution nennt, dem das vom Kopf Bezeichnete zugehört oder in dessen Zuständigkeitsbereich es fällt: Königspalast, Blattgrün, Stadtgärtner;

- auf Vergleichsrelationen, bei denen der Modifikator etwas nennt, das (unter wechselnden Gesichtspunkten) ähnlich ist wie das vom Kopf Bezeichnete: Milchglas (englisch milk glass) in der anderen Lesart: ,Glas, das ähnlich undurchsichtig/ opak ist wie Milch', Goldfisch (englisch goldfish, ungarisch aranyhal (,Gold“ + ,Fisch`)), Froschmann (engl. frog man, ungarisch békaember (,Frosch`+ ,Mann')), Satteldach (englisch saddle roof).

Diese Grundrelationen überlappen sich zum Teil, so dass man Komposita ohne Mehrdeutigkeit annehmen zu müssen - gelegentlich auf die eine oder andere von ihnen zurückführen kann. So kann man Tischbein auch als, eines der Beine, die ein Tisch hat' verstehen, somit als Zugehörigkeitsrelation. Viele Determinativkomposita verkörpern also ähnlich wie Possessivattribute eine 
der Spielarten possessiver Relationen, von der Besitzrelation bis zur Teil-Ganzes-Beziehung. Man vergleiche dazu die „semantische Landkarte der Possession“ in Kapitel 4, Abschnitt 6.1.

Die Auswahl aus solchen konzeptuellen Grundrelationen, die zur jeweils lexikalisierten oder auch nur usuellen Deutung führt, wird dann, wie angedeutet, in einem komplexen Zusammenspiel über die Wortbedeutungen der Teile und über das stereotypische Sachwissen gesteuert. Ein konkreter Diskurszusammenhang kann jedoch auch Schlussfolgerungen anstoßen, die das Gängige überschreiben.

Allerdings fügen sich nicht alle Komposita problemlos in das Prokrustesbett von Ober- und Unterbegriff. Ein Rotkehlchen ist keine rote Unterform der kleinen Kehlen, mit Dummkopf, Rothaut (englisch redskin), Schlitzohr, Blaustrumpf, Rotrock meint man nicht die genannten Körperteile oder Bekleidungsstücke, sondern die Lebewesen (Tiere oder Personen), die, so suggerieren wir, entsprechend ausgestattet sind. Es liegt also eine Metonymie vor: Man nennt einen Körperteil mit einer hervorstechenden Eigenschaft, ein typisches oder gar verräterisches Kleidungsstück mit bedeutungsvoller Farbe und meint das ganze Wesen. Bei Grünschnabel oder Hasenfuß kommt zur Metonymie noch eine metaphorische Übertragung vom Tier auf den Menschen hinzu. Solche ,Possessivkomposita“ sind in der Volks-Taxonomie der Tiergattungen, vor allem der Vogelspezies, beliebt. Im Deutschen und Englischen gibt es hier zum Teil parallele Bezeichnungen wie Blaukehlchen - bluethroat, Kreuzschnabel - crossbill, oder nur die eine Sprache verfährt so wie bei Rotkehlchen robin oder wheatear (wörtlich ,Weizenohr') - Steinschmätzer. In Bezug auf Menschen handelt es sich meist um negativ oder abschätzig Gemeintes: Sie werden dann z. B. herabgesetzt aufgrund des „dummen Kopfes“, des „grünen Schnabels“, den sie angeblich haben - oder auch des zur schnellen Flucht besonders geeigneten Fußes, der den Hasen auszeichnen soll - also wegen mangelnden Verstandes, Unreifheit oder Ängstlichkeit. Gerissene Menschen nennen wir Schlitzohren. Ein geschlitztes Ohr, so die eine Erklärungshypothese, konnten Handwerksgesellen sich zuziehen, wenn ihnen der gern getragene und auch als eiserne Reserve dienende goldene Ohrring als Strafe für ein Vergehen abgerissen wurde. Warum das dann für Durchtriebenheit steht, bleibt unklar; ebenso ist auch die ganze Strafmaßnahme historisch nicht belegt. Die andere Erklärung sieht im Schlitzohrigen gleich den Teufel..$^{50}$ Immerhin kann man in all diesen Fällen den Ausdruck für das Possessum von Possessivkomposita - also die Wurzel der Metonymie - als nach dem Muster der Determinativkomposita gebildet verstehen: der Kreuzschnabel, den ein Kreuzschnabel hat, ist ein Schnabel, der wie ein Kreuz geformt ist.

Ebenfalls auf der Possessivbeziehung beruhen im Altgriechischen die etwa in den Epen des Homer verbreiteten komplexen Adjektive wie kakó-bios (aus kakós ,schlecht') + bios ,Leben') ,ein schlechtes Leben habend“ oder hēdúoinos (aus hēdús 
,süß + oinos ,Wein'), süßen Wein habend‘. Possessivkomposita kann man auch als eine besondere Form der oder eine Brücke zu den ,exozentrischen` Komposita verstehen, denen mit „außerhalb“ des Wortes liegendem Kopf oder besser: kopflosen Komposita. Und damit sind wir beim nächsten Thema.

\subsection{Komposita zum dritten: Komposita mit linkem Kopf und exozentrische Komposita}

Nicht mehr in das Prokrustesbett der Determinativkomposita nach dem Vorbild germanischer Sprachen lassen sich zwei weitere Formen bringen, die uns hier noch kurz beschäftigen sollen: Für sie mögen die französischen Beipiele chapeau cloche (,Hut' +,Glocke') ,Topfhut' und gratte-ciel (,kratze' (Imperativ) + ,Himmel') ,Wolkenkratzer' stehen.

Bei einem chapeau cloche handelt es sich um einen Hut in Form einer Glocke, nicht etwa um eine Glocke in Form eines Huts. Der Kopf steht also links, nicht rechts wie bei den Determinativkomposita des Deutschen. Linksköpfige $\mathrm{N}+\mathrm{N}$ Komposita finden sich verbreitet im Französischen und anderen romanischen Sprachen. Allerdings sind sie semantisch längst nicht so volatil wie die rechtsköpfigen der germanischen Sprachen (oder auch des Ungarischen). Meist drücken sie eine Ähnlichkeitsbeziehung aus wie eben in chapeau cloche oder auch bei poisson-chat / poisson-lune / poisson-scie (,Katzenfisch', englisch catfish / ,Mondfisch“ / ,Sägefisch'). Oder den italienischen ,Fisch'-Komposita mit pesce spada ,Schwertfisch“ oder pesce palla ,Kugelfisch'. Oder aber es handelt sich um semantisch koordinative Strukturen wie in (un) bracelet-montre (,Armband + , Uhr'), das nicht nur deutsch Uhrenarmband entspricht, sondern auch deutsch Armbanduhr. Armbanduhr wiederum kann auch durch die Umkehrung (une) montre-bracelet wiedergegeben werden. Dies deutet darauf hin, dass die semantische Hierarchie unserer rechtsköpfigen Strukturen hier weniger ausgeprägt ist, wenn auch auf der morphosyntaktischen Ebene der linksstehende Kopf das Genus bestimmt. In den Plural aber setzt man beide Bestandteile; es heißt also bracelets-montres bzw. montres-bracelets - während im Deutschen nur der Kopf pluralisiert werden darf, wir also keine Armbänderuhren kennen und in Uhrenarmbänder -en als Fugenelement, nicht als Pluralmarker dient.

Beschränkt ist dieses Muster auch im Hinblick auf Rekursion. Zwar findet man etwa in Angebotslisten kaskadische Bildungen wie chapeau cloche feutre femme ,Frauenfilztopfhut‘. Aber ein Vorkommen in „normalen“ Texten ist - anders als beim deutschen Gegenstück - wohl kaum zu erwarten.

Kopflose oder ,exozentrische‘ Komposita bezeichnen Gegenstände, die nicht unter die von den Teilen bezeichneten Begriffe - weder den linken noch den 
rechten - fallen. Jene kopflastigen Komposita, die wir vor allem kennen, sind entsprechend vom ,endozentrischen` Typ. Eine in europäischen Sprachen bekannte Form, neben den Possessivkomposita, ist die folgende, mit der eine Art verkürzter syntaktischer Umschreibung des gemeinten Begriffs geliefert wird. ,Kratz(-den)Himmel' (frz. gratte-ciel) ist sozusagen die Bestimmung des Wolkenkratzers, ,Schneid-(den)-Stromkreis-ab“ (frz. coupe-circuit) gibt recht präzise an, was eine Sicherung tun soll, während ,Schneid(-die)-Gurgel-durch“ (frz. coupe-gorge) eine makabre Warnung davor ist, was Böswilligen in einer Spelunke oder einem anderen gefährlichen Ort durch den Kopf gehen mag. Der erste, verbale Teil des exozentrischen Kompositums ist (bei den er-Verben) formal identisch mit der Imperativform des Singulars und der 3. Person Singular Präsens oder auch einfach mit der maximal unmarkierten Verbform. Vergleichbares gilt auch für italienisch lavapiatti oder asciugacapelli, insofern als das erste mit ,Wasch(-die)-Teller', das zweite mit ,Trockne(-die)-Haare‘ jeweils die Spülmaschine und den Haartrockner umschreibt. Auch im Englischen ist dieser Typ vertreten, wenn auch nicht mehr als produktives Verfahren. Hinter englisch pickpocket verbirgt sich der Impuls ,Schnapp (-dir-die)-Tasche', den wir dem Taschendieb zuschreiben. Die Vogelscheuche erfüllt die Aufgabe eines ,Erschreck(-die)-Krähe‘ (englisch scarecrow).

Im Deutschen kennen wir nur vereinzelt Beispiele wie Störenfried und als entfernt damit verwandtes Phänomen die Umwandlung einer ganzen Phrase in ein Substantiv bei Pflanzennamen wie Rühr-mich-nicht-an oder Vergissmeinnicht. In meinem Heimatdialekt nennt man zudem einen Menschen, der sonstwo vielleicht als „Miesepeter“ bezeichnet würde, einen „Seltenfröhlich“. Auch der „Habenichts“ ist grammatisch vom selben Schlag.

\subsection{Partikelverben: die unorthodoxe Form der Wortbildung}

An verschiedenen Stellen in diesem Buch sind wir auf die so genannten ,Partikelverben' gestoßen, weil sie den Sprecher oder die Schreiberin wie auch den Linguisten oder die Linguistin vor Probleme stellen. Sei es, dass ihre Schreibung schwierig ist; ich erinnere an kopfstehen oder eislaufen (neben ablaufen und untertauchen) im Exkurs zur Substantivgroßschreibung in Kapitel 4 (Abschnitt 3.2). Sei es, dass ihr Zusammen- oder Getrenntvorkommen in verschiedenen Feldern oder Positionen im Satz aufmerken und an Parallelen zum Ungarischen denken lässt (vgl. Abschnitte 3.2 und 3.5 in Kapitel 5). Sei es, dass die Formenbildung von Anglizismen wie downloaden oder whatsappen (vgl. Unterkapitel 3) an manchen Stellen ein „Zweifelsfall“ ist.

Ich fasse kurz zusammen: Partikelverben des Deutschen bestehen aus einem Verb als zweitem Teil und einem ersten Teil, der aus verschiedenen Wortklassen 
stammen kann: Substantiven (wie bei brustschwimmen, kopfstehen), Adjektiven (wie bei blankziehen, glattbügeln, krankschreiben, wertschätzen), Adverbien (wie bei auseinanderfallen, herunterschauen oder auch downloaden) und Präpositionen (wie bei austrinken, zwischenlagern). Partikelverben werden auf dem ersten Teil betont. Die beiden Teile werden häufig ,syntaktisch' getrennt, nur bei Verbletztstellung sind sie immer vereint (wie in Zieht er jetzt blank / Er zieht jetzt blank versus dass er jetzt blankzieht). Wie man sieht, ist der Partikelteil, wenn man so will, ortsfest: Er verharrt in der rechten Klammer, nur das Finitum bewegt sich weg von - oder hin zu ihm. Sind sie syntaktisch vereinigt, können sich aber immer noch das $z u$ des Infinitivs oder das ge- des Partizips dazwischen zwängen und damit für eine ,morphologische‘ Trennung der Teile sorgen (wie bei Er braucht doch nicht blankzuziehen / Er hat jetzt blankgezogen). ${ }^{51}$

Könnte man also einfach Partikelverbfügungen der Syntax zuschlagen? Die Antwort ist: In manchen Fällen durchaus, in anderen auf keinen Fall. Bei Klavier spielen oder Rad fahren haben wir schon im Gegensatz zu Fällen wie eislaufen und brustschwimmen in Kapitel 4 für eine Sehweise als Syntagma plädiert. Auch glattbügeln und andere Verben mit adjektivischem Erstglied oder auseinanderfallen und andere Verben mit einem Adverb als Erstglied benehmen sich (fast) wie beliebige syntaktische Verbindungen aus Adjektiv oder Adverb + Verb. Oft wird dann zugunsten des Wortstatus geltend gemacht, dass eine idiomatische Bedeutung vorliege, also die Bedeutung der Gesamtheit sich nicht aus den Bedeutungen der beiden Teile berechnen lasse, wie dies bei einer syntaktischen Verbindung zu erwarten wäre. Nun gibt es aber (vgl. Unterkapitel 2) auch in der Syntax feste Fügungen mit speziellen Bedeutungen (gelber Sack, auf Anhieb). Das Kriterium ist also nicht hinreichend für die Entscheidung zwischen Syntax und Wortbildung. Zudem ist gerade bei Verbindungen aus Adjektiv oder Adverb + Verb Doppelsinnigkeit fast die Regel: „Sein gestreiftes Hemd ist glatt gebügelt [...]“ (ZEIT (Online-Ausgabe) vom 23.10.2003) versus „Die meisten Schwächen bügeln sich später von selbst glatt“ (profil vom 02.07.2012). Oder auch: „Ich habe mir vorgestellt, was passieren würde, wenn ein Außerirdischer einfach einmal auf die Erde herunterschaut [...]“ (Protokoll der Sitzung des Parlaments Landtag Rheinland-Pfalz am 14.09.2000) versus „Auch die Arroganz des nordbadischen Raums, das Herunterschauen auf die Pfalz und auf die Industriestadt Ludwigshafen, war schlimm“ (Protokoll der Sitzung des Parlaments Landtag Rheinland-Pfalz am 13.10.2005). Bei Adverb + Verb kann die Lage des Hauptakzents die idiomatisierte Verbindung von der freien Verbindung unterscheiden. Im ersten Fall liegt der Akzent normalerweise (aber nicht notwendigerweise) auf dem Adverb (wie in Ich möchte dich endlich 'wiedersehen). Im zweiten Fall trägt das Verb den Hauptakzent (wie in Ich möchte dich endlich wieder 'sehen und nicht nur deine Stimme hören). 
Wenn wir also partout bei Adjektiv oder Adverb + Verb Fälle von Wortbildung klar von Fällen der syntaktischen Fügung unterscheiden wollen, müssen wir uns durch eine ganze Reihe zum Teil nicht notwendiger oder hinreichender und zudem vergleichsweise „weicher“ Kriterien hangeln. Fügungen können z. B. mehr oder weniger idiomatisch sein: Bei glatt bügeln und herunterschauen genügt ein kleiner Schritt von einer körperlichen bzw. sensorischen Aktion zu jener unkörperlichen Aktion, die durch sie symbolisiert werden kann: Das Glattbügeln von Kleidungsstücken steht für die Retusche von Problemen, das Von-oben-hinunter-Schauen ist physischer Ausdruck angemaßter Überlegenheit und steht für Verachtung. Bei krankschreiben oder schwerfallen muss schon mehr an Übertragungsarbeit geleistet werden. Die Alternative Syntax oder Wortbildung wird der Gradualität des Phänomens in diesen Fällen nicht wirklich gerecht.

Anders bei austrinken, zwischenlagern und den Partikelverben mit einem präpositionalen ersten Teil generell. Hier, bei diesen ,präpositionalen Partikelverben', ist eine Auffassung als syntaktische Verbindung ganz ausgeschlossen, weil Präpositionen (zumindest im Deutschen) syntaktisch nicht mit Verbformen eine Verbindung eingehen oder sie ,regieren', sondern nur mit Nominalphrasen. Hier handelt es sich also zweifelsfrei um Wörter. Aber sind es nun Zusammensetzungen oder Ableitungen? Oder weder noch?

Für den Status als Komposita spricht einmal das Akzentmuster: Auch die unstrittigen Nominalkomposita, also z. B. Hutschachtel oder wunderschön, werden auf dem Erstglied betont. Und favorisiert nicht auch der schöne Gegensatz zwischen 'überstehen und über'stehen oder 'durchbohren und durch'bohren eine ebenso klare Alternative zwischen Komposition beim jeweils ersten und Derivation beim jeweils zweiten? Semantisch könnte es auch passen, denken wir an Beispiele wie Das Werkstück steht über bzw. Der Handwerker bohrt ein Loch durch. Bei 'überstehen und 'durchbohren geht es jeweils um ein Über-etwas-Stehen (z. B. über die Tischkante) bzw. ein Etwas-durch-etwas-Bohren (z. B. ein Loch durch die Wand). Es wird nur verschluckt oder als bekannt vorausgesetzt, dass dieses Etwas die Tischkante oder die Wand ist. Den Partikelverben fehlt hier einfach diese eine Valenzstelle, sie ist durch die Partikel quasi ,absorbiert‘. Bei den Gegenstücken mit Betonung des zweiten Teils geschieht Dramatischeres mit der Valenz und oft auch bedeutungsmäßig: über'stehen ist im Gegensatz zu stehen transitiv, und seine Bedeutung ,mit positivem Ende aus einer schlechten Lage (z. B. einer Krankheit) hervorgehen' hat mit dem einfachen stehen nur noch wenig zu tun. durch'bohren bleibt zwar konkret, aber die Argumente werden gegenüber einfachem bohren umstrukturiert. Man vgl. Sie bohrt ein Loch durch die Wand versus Sie durchbohrt die Wand.

Nun gibt es aber auch Evidenzen, die in Richtung Derivation deuten. Wie die „echten“ Präfixverben können präpositionale Partikelverben unbeschränkt in 
weitere Ableitungszyklen eintreten. Man vergleiche: ausstehen - ausstehbar unausstehbar - Unausstehbarkeit wie verstehen - verstehbar - unverstehbar Unverstehbarkeit. Auch gibt es Bildungen wie aufklaren oder abkupfern, bei denen nicht einfach eine Präposition und ein existentes Verb kombiniert werden, sondern erst im Zusammenschluss von Präposition und Adjektiv oder Präposition und Substantiv ein Verb entsteht. So etwas passiert bei Komposita nicht. Und auch die Partikelverben mit adverbialem Erstglied zeigen sich gegenüber diesen beiden Derivationsprozessen eher abgeneigt. In ganz DeReko gibt es z. B. nur ein einziges Wort, das mit unherunter beginnt, nämlich unherunterfallbar, das zudem nur einmal belegt ist. Und zwar mit diesem Satz aus einem eher scherzhaft gemeinten Artikel: „Oder man verwendet ein Zubehör, mit dem das Handy nahezu unherunterfallbar an der Hand befestigt wird“ (Süddeutsche Zeitung vom 19.06.2019). ${ }^{52}$ Verbalisierungen von Adjektiven oder Substantiven scheinen ganz ausgeschlossen zu sein: *etwas hineintüten versus etwas eintüten, *jemanden aus Deutschland herausbürgern versus jemanden aus Deutschland ausbürgern.

Es ergibt sich wohl folgendes Bild: Das Phänomen Partikelverben reicht von mehr oder weniger stark idiomatisierten Bildungen, die formal syntaktische Verbindungen sind, bis zu präpositionalen Partikelverben, die auch formal nur als Wörter zu analysieren sind. Die Lage des Wortakzents und die Trennbarkeit bleiben als Spuren syntaktischer Konstruktionsweise über die ganze Wegstrecke erhalten. Auch bei präpositionalen Partikelverben gibt es widersprüchliche Signale, die in Richtung Komposition bzw. Derivation weisen. Es handelt sich also am ehesten um einen eigenen janusköpfigen Wortbildungstyp.

Nicht nur das Deutsche, sondern auch das Englische und das Ungarische verfügen über Bildungen, die in ähnlicher Weise aus der Rolle fallen. Im Englischen geht es dabei um „verb-particle-combinations“ wie go in, give in oder take in, im Ungarischen um Verbindungen etwa direktionaler Adverbien wie be ,hinein', el ,weg', hozzá ,hinzu/dazu' mit einem Verb, z. B. mit megy ,gehen' 53

Wie im Deutschen können diese Verbindungen eine (mehr oder weniger) wörtliche - oder vielmehr aus zwei Wortbedeutungen komponierte - oder auch eine idiomatische Bedeutung haben. Englisch go in ist wörtlich zu verstehen als ,hineingehen', give in idiomatisch als ,nachgeben'. Partikel-Verb-Kombinationen mit idiomatischer Bedeutung, die so genannten ,phrasal verbs‘, spielen im Englischen eine ganz bedeutende Rolle. Die Verbindung take in kann sowohl wörtlich im Sinne von ,hineinbringen“ als auch idiomatisch im Sinne von ,hereinlegen, täuschen' verstanden werden. Da englisch in, out, over usw. sowohl den deutschen Präpositionen in, aus, über als auch den Adverbien hinein, hinaus, hinüber/darüber entsprechen, fällt die für das Deutsche wesentliche Unterscheidung zwischen Adverb + Verb-Kombinationen und präpositionalen Partikelver- 
ben hier flach: go out entspricht ausgehen und hinausgehen, flow over entspricht überfließen und darüberfließen. Ein Nebeneinander von wörtlicher und idiomatischer Bedeutung kann auch bei ungarischen Partikelverben vorliegen wie etwa bei hozzámegy, das sowohl ,zu jemandem hingehen‘ als auch ,jemanden heiraten‘ bedeuten kann.

Die stärkste Gemeinsamkeit zwischen den Partikelverben aller drei Sprachen ist ohne Zweifel die Trennbarkeit der beiden Teile, wobei nur die syntaktische Aufspaltung gemeint ist. Morphologische Trennung kommt nur im Deutschen vor. Wo die Teile landen, ist aber den sprachspezifischen Wortstellungsprinzipien geschuldet und damit unterschiedlich. So kann es im Englischen heißen:

She took in the parcel ,Sie holte das Paket herein / Sie nahm das Paket (an jemandes Stelle) an'

oder:

She took the parcel in

Bei einem Personalpronomen als Objekt allerdings muss die Partikel nach dem Objekt stehen. Man denke z. B. an den Beatles-Titel „We can work it out“ (zu deutsch etwa; „Wir können es hinkriegen“). Die Partikel ist also - mit Einschränkungen ähnlich beweglich wie ein reguläres Adverb oder eine adverbiale Bestimmung.

Im Ungarischen steht die Partikel unmittelbar vor dem Verb, also in der Fokusposition, nur dann, wenn kein anderes Satzglied im Fokus ist, wie etwa in:

Gabor el-ment ,Gabor ging weg‘

Ist dagegen ein anderes Satzglied fokussiert, räumt die Partikel die Position und kommt hinter das finite Verb zu stehen, wie etwa in:

A turisták mentek $\boldsymbol{e l}$,Die Tou'risten sind weggegangen“

Auch größere Entfernungen zwischen den beiden Teilen sind möglich.

In der Gesamtabrechnung zeigt sich, dass im Englischen und Ungarischen die Bildungen in höherem Maße syntaktisch sind und in geringerem Maße „wortig“ als im Deutschen, zumindest im Vergleich zu den präpositionalen Partikelverben. Im Englischen zeigt sich das z. B. deutlich daran, dass der Wortaufbau, also die Normalfolge ,Verb vor Partikel' dem Aufbau komplexer Wörter widerspricht. Man denke daran, dass es ja durchaus auch noch Überreste der alten Bildungsweise gibt, wo wie im Deutschen das Adverb mit dem Verb zu einem Kompositum zusammentritt (wie in overflow neben flow over). Aber die Verb + Partikel-Kombinationen sind weit in der Überzahl. Sie eignen sich auch bestens für die Konversion in Substantive. Substantive wie makeup, pickup, pullover wiederum werden, anders als die Verben, seit längerem eifrig ins Deutsche entlehnt. Jüngste Beispiele aus der 
Zeit der Coronakrise sind (der) Shutdown oder (der) Lockdown. Strukturell äquivalente Lehnübersetzungen ins Deutsche sind ausgeschlossenen. Bei der Wiedergabe durch Stillstand geht verloren, dass es sich hier um einen absichtlich herbeigeführten und verordneten Generalzustand handelt. Herunterfahren würde das eher treffen; mit diesem nominalisierten Infinitiv kann man jedoch nur die Handlung, nicht den Resultatszustand bezeichnen. ${ }^{54}$

Tritt man einen Schritt zurück, so erstaunt doch, dass gerade bei Verben sich in mehreren europäischen Sprachen - offensichtlich unabhängig voneinander diese Zwitter-Konstruktion zwischen Wort und aufspaltbarem Syntagma herausgebildet hat. Als Motor dahinter könnte man das syntaktische Primat des Verbs als Prädikat vermuten: In dieser syntaktischen Funktion regiert das finite Verb die anderen zentralen Satzglieder. Was liegt näher, salopp gesagt, als dass das Verb sich flexibel an entscheidenden Stellen im Satz einbringt, wenn es denn als komplexes Gebilde dazu in der Lage ist?

\section{Wort- und Begriffsbildung in anderen europäischen Sprachen und ein Blick über den Rand des Kontinents hinaus}

Schauen wir uns zunächst um in den Sprachen der Welt, so fallen - neben anderen in europäischen Sprachen nicht oder kaum vertretenen Möglichkeiten - zwei Phänomene auf, die ganz oder teilweise in die Wortbildung gehören könnten: Reduplikation und Inkorporation. Bei Reduplikation werden Teile eines Wortes oder auch der ganze Wortstamm in identischer oder auch abgewandelter Form wiederholt. In der Wortbildung auf dem europäischen Kontinent spielt Reduplikation eine marginale Rolle. In aller Regel geht es dabei um locker gemeinte Bezeichnungen für Halbseidenes, Irrelevantes und Ungeordnetes wie bei Hickhack, Hokuspokus, Mischmasch, Schickimicki, Tingeltangel, Wirrwarr oder auch englisch chitchat ,Geschwätz'. Auf das Englische gehen auch Wischiwaschi (englisch wishywashy), tipptopp (englisch tip-top) oder Pingpong (englisch ping-pong) zurück. Die im Prinzip unbeschränkte Wiederholung des Präfixes ur- wie in Ururgroßmutter bzw. urururalt bildet die Schleifenbildung in der Generationenfolge bzw. die Übersteigerung einer Qualität quasi ab, auch dies ein extravaganter Fall. ${ }^{55}$ Ähnlich wirkt auch die aus dem Genitiv des Pronomens grammatikalisierte Form aller wie in am allerallerbesten versus am allerbesten. Während diese ,emphatische Hervorhebung“ von Eigenschaften im Deutschen nur durch die Wiederholung eines an sich schon emphatischen Präfixes geschieht, wird etwa im Türkischen ein Teil des Adjektivstamms in modifizierter Form vorn angeheftet, wie etwa bei uzun ,lang“ 
versus upuzun ,sehr lang‘ oder güzel ,hübsch“ versus güpgüzel ,sehr hübsch‘. ${ }^{56}$ Im Deutschen haben wir nur tagtäglich und wortwörtlich als isolierte Inseln einer ähnlichen Art der Reduplikation.

In der morphologisch armen, ,isolierenden' westafrikanischen Sprache Yoruba z. B. spielt hingegen die Reduplikation als Mittel der Wortbildung eine bedeutende Rolle. So werden produktiv Verben durch partielle Reduplikation in Substantive überführt, wie bei lo versus lilo, gehen' / , das Gehen“ oder so versus siso ,sagen'/,das Sagen‘. Vollständige Verdopplung unter Einfügung der Partikel ki fügt einem Abstraktsubstantiv eine negative Note hinzu wie bei ijókiijó ,unvernünftiger Tanz' zu ijó ,Tanz‘. ${ }^{57}$

Inkorporation auf der anderen Seite ist ein gängiges Verfahren bei den so genannten ,polysynthetischen' Sprachen. Wir sind bereits am Ende von Kapitel 2 (Abschnitt 6.2) auf eine ihrer Vertreterinnen gestoßen, auf die irokesische Sprache Cayuga, und zwar bei der Frage, wie Prädikation und Referenz dort im Unterschied zu den europäischen Sprachen realisiert werden. Da konnten wir bereits die syntaktische Anbindung von pronominalen Affixen an oder auch Inkorporation in die Inhaltswörter beobachten. Aber insbesondere auch die Inkorporation von Substantiven (oder Wörtern, die für Gegenstandskonzepte stehen) in Verben (oder Wörter, die Tätigkeiten bezeichnen) ist ein charakteristisches Merkmal polysynthetischer Sprachen. So steht in Tab. 10 (s. folgende Seite) der Satz (a) für die uns als „normaler“ erscheinende Struktur aus inkorporiertem pronominalem Subjekt und selbstständigem direktem Objekt (,ein Ding`) während in Version (b) der Ausdruck für ,Ding‘ in die inkorporierte Struktur einbezogen wird. Es handelt sich um Guarani, eine in Paraguay gesprochene indigene Sprache:

Man kann -mba'e-jogua- in b) als komplexes Verb ,einkaufen“ betrachten. Aber bedeutet das notwendigerweise, dass hier Wortbildung im Sinne von Lexembildung vorliegt? Es könnte sich ja auch um eine durch den Diskurs, also z. B. die Informationsgewichtung gesteuerte Wahl zwischen Ausdrucksalternativen handeln, die nicht im Lexikon gespeichert sind, weder im mentalen noch gar in einem gedruckten oder digitalen. Dann würden hier die Sprecher jeweils aktual einer Regel an der Schnittstelle zwischen Syntax und Morphologie folgen. Diese Frage muss hier offen bleiben. ${ }^{58}$

Nun zurück zu den europäischen Sprachen. Sprachfamilienübergreifend wird auf jeden Fall ausgiebig von der Derivation Gebrauch gemacht, bei großen Unterschieden im Einzelnen. Was die Komposition angeht, sieht es etwas anders aus: Es gibt Sprachen mit hoher Kompositionsaktivität und solche mit geringer oder gar nur peripherer. Die germanischen Sprachen sind insgesamt kompositionsfreudig, wobei die größten Parallelen zum Deutschen erwartungsgemäß beim Niederländischen auftreten. Aber auch in den nordgermanischen Sprachen und dem Englischen ist die Bildung rechtsköpfiger Komposita, vor allem mit einem Substantiv als 
Tab. 10: Syntaktische Fügung und Inkorporation in Guarani.

\begin{tabular}{lll}
\hline a) & petei & mba'e \\
$\begin{array}{l}\text { A-jogua-ta } \\
\text { Ich-kaufe-Futur }\end{array}$ & ein & Ding \\
,ich werde etwas kaufen' & & \\
\hline
\end{tabular}

b)

A-mba'e-jogua-ta

Ich-Ding-kaufe-Futur

,ich werde einkaufen gehen“

Kopf, produktiv. Im Englischen allerdings und bis zu einem gewissen Grade auch in den festlandskandinavischen Sprachen ist es nicht immer leicht, zwischen einer syntaktischen Konstruktion mit einem unflektiert vorangestellten Ausdruck als Attribut und einem Kompositum zu unterscheiden. So wird etwa englisch gas cooker als syntaktische Konstruktion betrachtet, button hole hingegen als Kompositum. Eines der Unterscheidungskriterien ist, dass man das Attribut einer syntaktischen Konstruktion z. B. durch Koordination erweitern kann, den Modifikator eines Kompositums aber nicht: So ist [[gas and electric] cookers] ,Gas- und Elektroherde' möglich, aber kaum [[button und bullet] holes] ,? Knopf- und Kugellöcher'. Auch die finno-ugrischen Sprachen Ungarisch und Finnisch haben ausgedehnte Kompositionsmöglichkeiten, ebenso etwa das Griechische. Demgegenüber verfügen slawische Sprachen wie Polnisch oder Russisch zwar durchaus über meist rechtsköpfige Muster der Komposition, sie treten aber im Rahmen der Wortbildung hinter die hoch produktive Ableitung zurück. In romanischen Sprachen schließlich spielt die Komposition eher eine geringe Rolle, wobei, wie oben gezeigt, linksköpfige und exozentrische Strukturen überwiegen.

Guten Einblick in die unterschiedliche Neigung unserer Haupt-Kontrastsprachen zur Komposition gewinnen wir, wenn wir Bezeichnungs- und Begriffsbildungsstrategien im nominalen Bereich vergleichen. Im Deutschen dominieren hier die Determinativkomposita. Mit ihnen, das wurde oben gezeigt, werden Unterbegriffe zu dem vom Kopf des Kompositums - in rechtsköpfigen Sprachen wie dem Deutschen dem Zweitglied - bezeichneten Begriff gebildet. Der Modifikator, das Erstglied, liefert dabei in aller Regel nur einen Indikator für den prinzipiell offenen semantischen Modus der Unterbegriffsbildung - denken wir zurück an Hutschachtel oder Goldfisch oder auch an Buchhandlung oder Blumengeschäft. Zunächst einmal gilt: Semantische Äquivalente in den verschiedenen Sprachen müssen nicht der Logik von Ober- und Unterbegriff folgen: Ein deutsches Kompositum kann einem Simplexlexem entsprechen oder auch einem Derivat. So gibt es im Polnischen ein Suffix -arnia/-alnia, das zur Ableitung von Ortsbezeichnungen dient, also unserem 
-(er)ei wie in Bäckerei ähnelt. Nur wird es sehr viel breiter angewendet, so dass wir nicht nur piekarnia ,Bäckerei“ (zu piec ,Backofen') haben, sondern auch z. B. księgarnia ,Buchhandlung' (zu księga, ältere Form von książka ,Buch') und kwiaciarnia ,Blumengeschäft‘ (zu kwiat ,Blume‘) oder sypialnia ,Schlafzimmer‘ (zu sypiać ,zu schlafen pflegen').

Begriffsbildung nach dem Oberbegriff-Unterbegriff-Schema (bzw. gemäß genus proximum und differentia specifica) kann aber auch auf andere Weise geschehen: statt durch Komposition durch syntaktische Komplexbildung. Für diese, die Bildung syntaktischer Komplexe, gibt es wieder mehrere Möglichkeiten - immer vorausgesetzt, dass der Ausdruck für den Oberbegriff syntaktisch als Kopf und der Modifikator als Attribut realisiert wird. Das simple Nacheinander von unflektiertem modifizierendem Substantiv, Adjektiv oder Partizip, gelegentlich auch Adverb und substantivischem Kopf, im Englischen wurde schon erwähnt. Beispiele sind gas cooker, red wine ,Rotwein', washing machine ,Waschmaschine‘, downward tendency ,Abwärtstrend‘.

Genereller verbreitet ist auf der einen Seite die Attribuierung eines - nach allen Regeln der jeweiligen Sprache flektierten - Adjektivs wie bei französisch poisson rouge ,Goldfisch'. Sprachübergreifend werden da auch aus Substantiven abgeleitete Adjektive eingesetzt wie in französisch vacances scolaires, polnisch wakacje szkolne ,Schulferien'. Die Adjektive scolaire bzw. szkolny gehören jeweils zu dem Substantiv in der Bedeutung ,Schule‘. Die wörtliche Entsprechung ,schulische Ferien“ jedoch ist im Deutschen ungebräuchlich. Im Ungarischen steht das Suffix - $i$ als nahezu unbeschränkt einsatzfähiges Mittel der Adjektivierung von Substantiven zur Verfügung, aber auch von Verben und sogar Wortgruppen. Und solche ,Relationsadjektive، (vgl. auch Kapitel 4 Abschnitt 3.3) sind dann auch ein bevorzugtes Instrument der Unterbegriffsbildung, wie etwa bei női kabát ,Damenmantel (Dame.ADJ + Mantel) oder bei állati hang ,Tierstimme‘ (Tier.ADJ + Stimme). Das Deutsche ist übrigens, was die Bildung von Relationsadjektiven angeht, nicht so klar. Da werden unterschiedliche Suffixe herangezogen wie -lich in königlich oder -isch in tierisch oder das entlehnte -al in global. Diese haben aber, anders als im Ungarischen, oft auch eine qualitative Bedeutung (wie in den zweideutigen Ausdrücken fürstliches Palais oder tierisches Verhalten). Und manchmal gibt es gar kein Relationsadjektiv. dämlich etwa ist nicht aus Dame abgeleitet, sondern hängt wie auch das bairische damisch mit dem niederdeutschen Verb dämelen (vgl. standarddeutsch taumeln) zusammen. Ein Relationsadjektiv im neutralen Sinne von ,zu einer Dame gehörig / auf Damen bezogen' steht nicht zur Verfügung, wie auch z. B. weder herrlich noch herrisch rein relational gebraucht werden können, obwohl deren Ableitung aus Herr außer Frage steht.

Neben adjektivischen sind an zweiter Stelle Possessivattribute zu nennen. Wie generell bei diesen Attributen (vgl. Kapitel 4, Abschnitt 6.1) finden wir hier 
im Französischen die Präposition de wie in pot de chambre ,Nachttopf', im Englischen den pränominalen Genitiv wie in bird's nest ,Vogelnest' und die Präposition of wie in weapons of mass destruction ,Massenvernichtungswaffen" und im Polnischen den Genitiv wie in miejsce urodzenia ,Geburtsort' (Ort + Geburt.GEN). Neben den genannten semantisch leeren, nur Zugehörigkeit anzeigenden Präpositionen finden sich gelegentlich auch andere, wie etwa in englisch partner in crime ,Komplize‘, attorney-at-law ,Rechtsanwalt' oder in französisch moulin à café ,Kaffeemühle` oder médecin en chef ,Oberarzt` oder auch bei polnisch ksiażka dla dzieci ,Kinderbuch` (wörtlich ,Buch für Kinder`). In den erwähnten präpositionalen Konstruktionen des Englischen und Französischen hat das Attribut keinen Artikel. Es heißt nicht: pot de la chambre oder partner in the crime. Solche syntaktisch reduzierten Formen kann man als Indiz für die fehlende Referenzialität des Attributs werten. Es geht nicht um bestimmte Zimmer, in dem sich der Topf befände, oder um ein bestimmtes Verbrechen, sondern um das Konzept Zimmer bzw. Verbrechen. Allerdings fehlt der Artikel nicht notwendigerweise; man denke an man of the world ,Weltmann“ oder journée de la femme ,Frauentag' oder auch glace au chocolat ,Schokoladeneis‘, wo wir es bei au mit einer Verschmelzung aus der Präposition $a ̀$ und dem definiten Artikel zu tun haben.

Auch im Deutschen verfügen wir über syntaktische Formen der Begriffsbildung; ich erinnere an den gelben Sack, den blauen Montag oder auch an das Zimmer mit Dusche. Auch Konstruktionen mit Genitivattribut kommen vor. Allerdings immer mit dem definiten Artikel wie bei Mann der Tat, Bild des Jammers. Eine syntaktische Reduktion etwa $\mathrm{zu}$ *Bild Jammers verbietet sich. „Begleiterlose“ Substantive im Genitiv sind nicht erlaubt.

Die folgende Tabelle stellt Beispiele für die Begriffsbildung nach dem Oberbegriff-Unterbegriff-Schema in unseren Vergleichssprachen zusammen, geordnet nach ihrer Bildungsweise (Wortebene versus syntaktisch reduzierte Konstruktion versus syntaktisch voll ausgebaute Konstruktion). Die unterschiedlich bedeutsame Rolle der drei Bildungsweisen in den einzelnen Sprachen sollen die Produktivitätswerte (,hoch produktiv‘ versus ,wenig produktiv‘ versus ,peripher') verdeutlichen. 
Tab. 11: Verfahren der nominalen Begriffsbildung in den Vergleichssprachen.

\begin{tabular}{|c|c|c|c|}
\hline & Auf Wortebene & syntaktisch reduziert & syntaktisch voll ausgebaut \\
\hline \multirow[t]{2}{*}{ Deutsch } & hoch produktiv & wenig produktiv & wenig produktiv \\
\hline & $\begin{array}{l}\text { Raubvogel, Nervenkrieg, } \\
\text { Königshaus, } \\
\text { Königssohn, Haustür, } \\
\text { Atom-/Nuklearwaffe, } \\
\text { Hausschlüssel, } \\
\text { Linienschiff }\end{array}$ & Mann von Welt & $\begin{array}{l}\text { schwarzes Brett, } \\
\text { Tag der Arbeit/Tag der } \\
\text { offenen Tür }\end{array}$ \\
\hline \multirow[t]{2}{*}{ Englisch } & hoch produktiv & hoch produktiv & hoch produktiv \\
\hline & $\begin{array}{l}\text { front-door, latchkey, } \\
\text { notice board/ } \\
\text { notice-board } \\
\text { Labour Day }\end{array}$ & $\begin{array}{l}\text { bird of prey, war of } \\
\text { nerves }\end{array}$ & $\begin{array}{l}\text { royal house, nuclear } \\
\text { weapon } \\
\text { man of the world, ship of } \\
\text { the line }\end{array}$ \\
\hline \multirow[t]{2}{*}{ Französisch } & peripher & hoch produktiv & hoch produktiv \\
\hline & $\begin{array}{l}\text { journée portes ouvertes } \\
\text { [Tag Tür.PL offen.PL] }\end{array}$ & $\begin{array}{l}\text { oiseau de proie, bateau } \\
\text { de ligne, (alternativ zu } \\
\text { tableau noir: tableau } \\
\text { d'affichage) }\end{array}$ & $\begin{array}{l}\text { maison royale, arme } \\
\text { nucléaire } \\
\text { guerre des nerfs, fils du } \\
\text { roi, porte de la maison, clé } \\
\text { de la maison, fête du } \\
\text { travail } \\
\text { tableau noir }\end{array}$ \\
\hline \multirow[t]{2}{*}{ Polnisch } & peripher & peripher & hoch produktiv \\
\hline & & & $\begin{array}{l}\text { ptak drapieżny [Vogel } \\
\text { räuberisch.M] } \\
\text {,Raubvogel, } \\
\text { drzwi zewnętrzne } \\
\text { [Tür außen.PL] } \\
\text { próba nerwów [Probe Nerv. } \\
\text { GEN.PL],Nervenkrieg‘, klucz } \\
\text { od domu [Schlüssel ab } \\
\text { Haus.GEN] ,Hausschlüssel‘ } \\
\text { tablica ogłoszeń } \\
\text { [Tafel Aushang.GEN.PL] } \\
\text {,schwarzes Brett‘ }\end{array}$ \\
\hline
\end{tabular}


Tab. 11 (fortgesetzt)

\begin{tabular}{|c|c|c|c|}
\hline & Auf Wortebene & syntaktisch reduziert & syntaktisch voll ausgebaut \\
\hline \multirow[t]{2}{*}{ Ungarisch } & hoch produktiv & peripher & produktiv \\
\hline & $\begin{array}{l}\text { uralkodóház [uralkodó } \\
\text { „Herrscher` ház ,Haus“ } \\
\text { idegháború [ideg ,Nerv“ } \\
\text { háború Krieg‘] } \\
\text { kapukulcs [kapu ,Tor‘ } \\
\text { kulcs ,Schlüssel‘] } \\
\text { atomfegyver [atom } \\
\text { „Atom‘ fegyver ,Waffe‘] }\end{array}$ & & $\begin{array}{l}\text { bejárati ajtó [Eingang.ADJ } \\
\text { Tür] } \\
\text { nyílt nap [offen Tag] ,Tag } \\
\text { der offenen Tür‘ } \\
\text { a munka ünnepe [DEF.ART } \\
\text { Arbeit Tag.POss] ,Tag der } \\
\text { Arbeit‘ }\end{array}$ \\
\hline
\end{tabular}

